\title{
Magnetic and Multifunctional Magnetic Nanoparticles in Nanomedicine: Challenges and Trends in Synthesis and Surface Engineering for Diagnostic and Therapy Applications
}

\author{
Laudemir Carlos Varanda ${ }^{1}$, \\ Miguel Jafelicci Júnior ${ }^{2}$ and Watson BeckJúnior ${ }^{1}$ \\ ${ }^{1}$ Institute of Chemistry of São Carlos - University of São Paulo, Colloidal Materials Group, \\ 2Institute of Chemistry of Araraquara - São Paulo State University, \\ Labor. of Magnetic Materials and Colloids,
} Brazil

\section{Introduction}

Today, the nanotechnology has achieved a development level reaching a stage where it is possible to produce and specially tailor the functional properties of nanoparticles (NPs) for biomedical and biotechnological applications (Gupta et al., 2007; Gupta \& Gupta, 2005; Pankhurst et al., 2009). Among different types of NPs, magnetic (MNPs) and more recently, multifunctional magnetic nanoparticles (MFMNPs) have attracted a great deal of attention in nanomedicine over the past decade. These functionalized nanomagnets can be directly injected onto the body vessels and properly manipulated by an external magnetic force. The action at a distance and the non invasive technique provide tremendous advantages for these NPs uses, making these nanomaterial ideal for either in vitro or in vivo biomedical applications (de Dios \& Díaz-Garcia, 2010; Lu et al., 2007; Salgueirino-Maceira \& CorreaDuarte, 2007). In the biomedicine area, their applications including magnetic resonance contrast agent in Magnetic Resonance Imaging (MRI), magnetohyperthermia for cancer treatment, magnetic force-assisted drug delivery, tissue repair, cell and tissue targeting and transfection, and protein isolation (Lu et al., 2007; Sanvicens \& Marco, 2008; Varanda et al., 2008). In this context, the combination of nanotechnology and molecular biology has developed into an emerging new class of nanomagnetics for biomedicine, which combine the MNP properties and the most modern surface engineering techniques resulting in biocompatible and bioselectable MFMNPs (de Dios \& Díaz-Garcia, 2010; Majewski \& Thierry, 2007; Salgueirino-Maceira \& Correa-Duarte, 2007; Selvan et al., 2010).

Down to the nanoscale, on the order of around two dozen or less, the magnetic particles change from paramagnetic to superparamagnetic (SPM) behavior, where magnetic moment of the particle as a whole is free to fluctuate in response to thermal energy, while the individual atomic moments maintain their ordered state relative to each other. Thus, the superparamagnetic NPs can only be magnetized in the presence of an external magnetic field and do not retain any magnetism after removal of the magnetic field, which makes 
them capable of forming stable colloids in a physio-biological medium (Lu et al., 2007; Majewski \& Thierry, 2007; Santos et al., 2008; Sorensen, 2001; Varanda et al., 2002a; Varanda et al., 2001; Varanda et al., 2007; Varanda et al., 2008; Varanda \& Jafelicci, 2006). Combining the SPM behavior with appropriate surface functionalizations, besides other intrinsic NPs properties such as low cytotoxicity, bioactivity and ability to conjugate with optically active molecules or compounds, makes their multifunctionalized nanomaterials strong biomedical tools for using in sensing, diagnostic or therapy fields. It appears reasonable to accurately consider that the aim of surface modification is not only to stabilize the NP suspension in vitro and govern their in vivo fates, but also to minimize the remnant magnetization. It is now recognized that internalization of particle also depends strongly on the size of the magnetic particle (Gupta et al., 2007). In addition, successive surface modifications realized to obtain functional or multifunctional NPs generally require additions of the non-magnetic materials on MNPs surface. Thus, at the final of the functionalization process, the magnetic core emanation has been dramatically decreased and the efficient NP application was strongly compromised (Selvan et al., 2010; Sun et al., 2008; Varanda et al., 2008). Besides the morphological strict control required for the MNPs, which have been effectively achieved due to advances in synthetic routes, their use in biomedicine is guided by two key challenges: (i) the surface engineering to promote the chemical/biological functionalizations that lead to required biocompatibility and bioselectivity and (ii) improving the magnetic properties of the core in order to stand different functionalizations keeping the magnetic emanation at high enough levels for their effective applications. According to exposed, this Chapter focuses on the synthesis, protection, functionalization, and applications of the MNPs to the biomedical areas, as well as emphasizing the features of magnetic properties of nanostructured systems. In addition, also describe some potentially useful design and applications of MFMNPs for biomedicine, which have been attracting increased research efforts because of their easily accessible multimodality.

\section{Features and required properties of the magnetic nanoparticles}

According to several studies reported in the literature relating MNPs for biomedical applications and properly summarized in a bright review published by Gupta et al. (Gupta \& Gupta, 2005), the effectiveness of these NPs depends upon:

a. SPM behavior and high magnetic susceptibility for effective magnetic response even after multifuncionalization with non-magnetic compounds;

b. narrow particle size distributions with size ranging from 6 to $20 \mathrm{~nm}$. Particles below a critical size $(\sim 20 \mathrm{~nm})$ would consist of a single magnetic domain (state of uniform magnetization at any field with superparamagnetism and high saturation magnetization values). In addition, the particles in this size range are rapidly removed through extravasations and renal clearance besides avoiding the capillary embolism.

c. tailored/targeting surface chemistry for specific functionalization.

Fundamental changes in the magnetic structure of ferro, ferri, and even antiferromagnetic materials when sizes are dramatically reduced for the nanoscale can be observed in the two most important effects, i.e., finite-size and highest-surface. In macroscopic scale or in large magnetic particles, there are magnetic domains regions (spins pointing in the same directions and acting cooperatively) with uniform magnetization separated by domain walls. The domain walls formation is driven by the balance between magnetostatic energy $\left(\Delta E_{M}\right)$, directly proportional to the material volume, and the domain-wall energy $\left(E_{D W}\right)$, 
which increases proportionally to the interfacial area between domains. As the particle size decreases toward some critical particle diameter $\left(D_{C}\right)$, the formation of domain walls becomes energetically unfavorable leading to the single-domain state. The multidomain to single-domain state limit is reached when $\Delta E_{M}=E_{D W}$ and the $D_{C}$ values can be easily calculated for many materials according to the magnetic particle properties such as magnetization, anisotropy constant, particle shape, etc (Batlle \& Labarta, 2002). Changes in magnetization can no longer occur through domain-wall motion and instead require the coherent rotation of spins resulting in large coercivities. A single-domain particle, on the other hand, is uniformly magnetized with all the spins aligned in the same direction. The magnetization will be reversed by spin rotation since there are no domain walls to move. This is the reason for the very high coercivity observed in the small NPs (Lu et al., 2007).

Continuos decreasing in the particle size below the single-domain value increasingly affect the spins by thermal fluctuations and the system becomes SPM (Salgueirino-Maceira \& Correa-Duarte, 2007; Sorensen, 2001). Under SPM behavior, the mechanism of magnetization reversal can only occur via the rotation of the magnetization vector from magnetic easy axis to another via a magnetically hard direction (Stoner \& Wohlfarth, 1948). However, the superparamagnetismo can be understood considering the magnetic anisotropy energy per particle, which is responsible for holding the magnetic moments along a certain direction. This energy barrier to moment reversal has several origins including both intrinsic and extrinsic effects, such as the magnetocrystalline and shape anisotropies, respectively, but used as a simplest form expressing the uniaxial effect or an effective anisotropy constant, $K_{\text {eff. }}$ This energy barrier is given by:

$$
E=K_{e f f} V \sin ^{2} \theta
$$

where $V$ is the particle volume and $\theta$ is the angle between the magnetization and the easy axis. With decreasing particle size, the thermal energy $k_{B} T$ exceed the energy barrier $K_{\text {eff }} V$, in which $k_{B}$ and $T$ is the Boltzmann's constant and the temperature, respectively. This direct proportionality between $E$ and $V$ is the reason that superparamagnetism (the thermally activated flipping of the net direction of the magnetic moment) is very important for small particles, because for them $E$ is comparable to thermal energy at room temperature. For $k_{B} T$ $>K_{\text {eff }} V$ the system behaves like a paramagnetic, instead of atomic magnetic moments, there is now a giant (super) moment inside each particle. The underlying physics of superparamagnetism is founded on activation for the relaxation time $\tau$ of particle net magnetization given by Néel-Brown (Eq. 2) (Lu et al., 2007; Sorensen, 2001) where $\tau_{0} \approx 10^{-9} \mathrm{~s}$.

$$
\tau=\tau_{0} \exp \left(K_{e f f} V / k_{B} T\right)
$$

Thus, it is important to recognized that observations of superparamagnetism are implicitly dependent not only the temperature, but also on the measurement time, $\tau_{m}$, of the used experimental technique (Salgueirino-Maceira \& Correa-Duarte, 2007). If the particle magnetic moment reverses at times shorter than the experimental time scale, the system is in a SPM state, if not, it is in the so-called blocked state. The temperature, which separates these two regimes, the so-called blocking temperature, $T_{B}$, can be calculated by considering the time window of the measurement. The blocking temperature depends on the effective anisotropy constant, the size of the particles, the applied magnetic field, and the experimental measuring time. For example, if the blocking temperature is determined using 
a technique with a shorter time window, such as ferromagnetic resonance which has a $\tau \approx$ $10^{-9} \mathrm{~s}$, a larger value of $T_{B}$ is obtained than the value obtained from $d c$ magnetization measurements. Moreover, a factor of two in particle diameter can change the reversal time from 100 years to 100 nanoseconds. While in the first case the magnetism of the particles is stable, in the latter case the assembly of the particles has no remanence and is SPM.

The second observed effect as the particle size decreases is related to the large percentage of all atoms in the NPs is surface atoms. This characteristic implies that surface and/or interface phenomena become more significant and important for the nanosized system properties, such as reactivity, and colloidal/chemical stabilities. According to the NP size and structure, it is usual to find about $60-70 \%$ of the total number of spins as surface spins. Immediate consequence of the large surface atoms/bulk atoms ratio is the local breaking of the structure symmetry might lead to changes in the band structure, lattice constant, and/or atoms coordination, which make an important contribution, besides other materials properties, to the NP magnetization. Under these conditions, surface/interface effects such as surface anisotropy occur and, in addition, according to the phases present on the NP surface and bulk, core-surface exchange anisotropy or interactions take place changing the resulting magnetic properties (Benitez et al., 2008; Hyeon et al., 2001; Hyeon, 2003b; Lu et al., 2007; Varanda et al., 2008).

\section{Synthesis of magnetic nanoparticles}

It has long been of scientific and technological challenge to synthesize the MNPs of customized size and shape (Gupta \& Gupta, 2005). In a general way, physical methods such as gas phase deposition and electron beam lithography are elaborate procedures that suffer from the inability to control the size of particles in the nanometer size range (Pratsinis \& Vemury, 1996; Rishton et al., 1997). The wet chemical routes to MNPs are simpler, more tractable and more efficient with appreciable control over size, chemical composition and sometimes even the shape of the NPs (Hyeon, 2003b; Malheiro et al., 2007; Santos et al., 2008; Sun et al., 2000; Sun \& Zeng, 2002; Varanda \& Jafelicci, 2006). Considering the high number of potential applications for high quality MNPs, especially for iron oxide case focused in the biomedical applications, it is not surprising that numerous synthetic routes have been described with different level of control on the size, polydispersity, shape, and crystallinity. Concerning only the wet chemical routes, the MNPs have been synthesized with a number of different compositions and phases, including iron oxides, such as $\mathrm{Fe}_{3} \mathrm{O}_{4}$ and $\gamma$ - $\mathrm{Fe}_{2} \mathrm{O}_{3}$ (Hyeon et al., 2001; Mornet et al., 2006; Sun \& Zeng, 2002), pure metals, such as Fe, Ni and Co (Puntes et al., 2001), spinel-type structure as ferrite of Mg, Mn, and Co (Park et al., 2004), as well as alloys, such as CoPt and FePt (Varanda \& Jafelicci, 2006). Especially during the last few years, many publications have described efficient synthetic routes to shapecontrolled, highly stable, and monodisperse MNPs. Several popular methods including coprecipitation, thermal decomposition/reduction, micelle synthesis, hydrothermal synthesis, and laser pyrolysis techniques can all be directed at the synthesis of high-quality MNPs. The most widely general accepted mechanism of the particles preparation in the solution under optimum synthetic conditions takes place by the rapid and homogenous formation of nuclei in a supersaturated medium, followed by controlled crystal growth, according to the wellknown LaMer's diagram (LaMer \& Dinegar, 1950). The latter process is controlled by mass transport and by the surface equilibrium of addition and removal of individual monomers, i.e., atoms, ions, or molecules. Hereby, the driving force for monomer removal increases 
with decreasing particle size. Thus, within an ensemble of particles with slightly different sizes, the large particles will grow at the cost of the small ones. This mechanism is called Ostwald ripening and is generally believed to be the main path of crystal growth. Magnetite particles obtained under different synthetic conditions, for example, may display large differences regarding their magnetic properties. These differences are attributed to changes in structural disorder, creation of antiphase boundaries, or the existence of a magnetically dead layer at the particle surface (Gupta \& Gupta, 2005). The saturation magnetization (Ms) values found in nanostructured materials are usually smaller than the corresponding bulk phases, provided that no change in ionic configurations occurs. Accordingly, experimental values for Ms in magnetite NPs have been reported to span the 30-50 emu/g range, lower than the bulk magnetite value of $90 \mathrm{emu} / \mathrm{g}$. Many studies have been reported on the origin of the observed reduction in magnetization in fine magnetic particles generally concerning the high-surface effects. The first studies on the decrease in magnetization performed in $\gamma$ $\mathrm{Fe}_{2} \mathrm{O}_{3}$ showed that this reduction is due to the existence of noncollinear spins at the surface. Also, in magnetite fine particles, Varanda et al. have reported a linear correlation between saturation magnetization and particle size, suggesting that defects at the particle surface can influence the magnetic properties. The surface curvature of the NP was much larger for smaller particle size, which encouraged disordered crystal orientation on the surface and thus resulted in significantly decreased Ms in smaller NPs (Varanda et al., 2002b). In this context, advancement in the use of magnetic particles for biomedical applications depends on the new synthetic methods with better control of the size distribution, magnetic properties and the particle surface characteristics. Typical and representative discussion of each main synthetic pathway in a general form is presented and the main features of the different routes are summarized in the Table 1. Today, the most used MNPs as potential magnetic materials for biomedical applications are based on the magnetic iron oxide NPs, generally described as SPION (SPM iron oxide nanoparticles) (Roca et al., 2009). Nevertheless, most of the NPs available to date have been prepared using variations of the aqueous co-precipitation method. In these processes, a nucleation phase is followed by a growth phase with good control over de particle size and polydispersity. Iron oxides, either $\mathrm{Fe}_{3} \mathrm{O}_{4}$ (magnetite) or $\gamma-\mathrm{Fe}_{2} \mathrm{O}_{3}$ (maghemite), can be synthesized from aqueous mixture of $\mathrm{Fe}^{2+}$ and $\mathrm{Fe}^{3+}$ salt solutions by the addition of a base under inert atmosphere at controlled temperature. The size, shape, and chemical composition of the MNPs are strongly dependents on the salts (e.g. chlorides, sulfates, nitrates, etc.), the $\mathrm{Fe}^{2+} / \mathrm{Fe}^{3+}$ ratio, the reaction temperature, the $\mathrm{pH}$ value and ionic strength of the medium. According to the thermodynamics of this reaction, a complete precipitation of $\mathrm{Fe}_{3} \mathrm{O}_{4}$ should be expected between pH 9 and 14, while maintaining a molar ratio of $\mathrm{Fe}^{3+}: \mathrm{Fe}^{2+}$ is 2:1 under a nonoxidizing oxygen free environment (Cornell \& Schwertmann, 2003).

Magnetite NPs are not also very stable under ambient conditions, and are easily oxidized to maghemite or dissolved in an acidic medium. Since maghemite is a ferrimagnet, oxidation is the minor problem. Therefore, magnetite particles can be subjected to deliberate oxidation to convert them into maghemite. This transformation is achieved by dispersing them in acidic medium, then addition of iron(III) nitrate. The maghemite particles obtained are then chemically stable in alkaline and acidic medium. However, even if the magnetite particles are converted into maghemite after their initial formation, the experimental challenge in the synthesis of MNPs by co-precipitation lies in control of the particle size and thus achieving a narrow particle size distribution. 


\begin{tabular}{|c|c|c|c|c|c|c|c|c|}
\hline \multirow{3}{*}{$\begin{array}{l}\text { Synthetic } \\
\text { method }\end{array}$} & \multicolumn{8}{|c|}{ Nanoparticle characteristics } \\
\hline & \multicolumn{2}{|r|}{ Size } & \multirow{2}{*}{$\begin{array}{l}\text { Shape } \\
\text { control }\end{array}$} & \multirow{2}{*}{ Synthesis } & \multicolumn{3}{|c|}{ Reaction } & \multirow{2}{*}{$\begin{array}{l}\text { Surface- } \\
\text { capping } \\
\text { agents }\end{array}$} \\
\hline & Range & Distribution & & & Temperature & Time & Yield & \\
\hline $\begin{array}{l}\text { Aerosol/vapor } \\
\text { (pyrolisys) }\end{array}$ & $\begin{array}{l}5-60 \\
\mathrm{~nm}\end{array}$ & Broad & Good & $\begin{array}{l}\text { Complicated, } \\
\text { vacuum/ } \\
\text { controlled } \\
\text { atmosphere }\end{array}$ & $\begin{array}{l}\text { High/ } \\
\text { very high }\end{array}$ & $\begin{array}{l}\text { Minutes } \\
\text { /hours }\end{array}$ & Medium & $\begin{array}{l}\text { Needed, } \\
\text { after } \\
\text { reaction }\end{array}$ \\
\hline Gas deposition & $\begin{array}{l}5-50 \\
\mathrm{~nm}\end{array}$ & Narrow & Good & $\begin{array}{l}\text { Complicated, } \\
\text { vacuum/ } \\
\text { controlled } \\
\text { atmosphere }\end{array}$ & Very high & Minutes & $\begin{array}{l}\text { High/ } \\
\text { scalable }\end{array}$ & $\begin{array}{l}\text { Needed, } \\
\text { after } \\
\text { reaction }\end{array}$ \\
\hline Sol-gel & $\begin{array}{l}3-150 \\
\mathrm{~nm}\end{array}$ & $\begin{array}{l}\text { Narrow/ } \\
\text { broad }\end{array}$ & Good & Simple & $20-90^{\circ} \mathrm{C}$ & $\begin{array}{l}\text { Hours/ } \\
\text { days }\end{array}$ & Medium & $\begin{array}{l}\text { Needed, } \\
\text { during } \\
\text { reaction }\end{array}$ \\
\hline Co-precipitation & $\begin{array}{l}10-50 \\
\mathrm{~nm}\end{array}$ & $\begin{array}{l}\text { Broad/ } \\
\text { narrow }\end{array}$ & Poor & Very simple & $20-90^{\circ} \mathrm{C}$ & Minutes & $\begin{array}{l}\text { High/ } \\
\text { scalable }\end{array}$ & $\begin{array}{l}\text { Needed, } \\
\text { during } \\
\text { reaction }\end{array}$ \\
\hline $\begin{array}{l}\text { Thermal } \\
\text { decomposition }\end{array}$ & $\begin{array}{l}2-20 \\
\mathrm{~nm}\end{array}$ & Very narrow & $\begin{array}{l}\text { Very } \\
\text { good }\end{array}$ & $\begin{array}{l}\text { Complicated, } \\
\text { inert atmosphere }\end{array}$ & $100-330^{\circ} \mathrm{C}$ & Hours & $\begin{array}{l}\text { High/ } \\
\text { scalable }\end{array}$ & $\begin{array}{l}\text { Needed, } \\
\text { during } \\
\text { reaction }\end{array}$ \\
\hline Microemulsion & $\begin{array}{l}4-15 \\
\mathrm{~nm}\end{array}$ & Narrow & Good & Complicated & $20-70^{\circ} \mathrm{C}$ & $\begin{array}{l}\text { Hours/ } \\
\text { days }\end{array}$ & Low & $\begin{array}{l}\text { Needed, } \\
\text { during } \\
\text { reaction }\end{array}$ \\
\hline Hydrothermal & $\begin{array}{l}10-150 \\
\mathrm{~nm}\end{array}$ & Narrow & $\begin{array}{l}\text { Very } \\
\text { good }\end{array}$ & $\begin{array}{l}\text { Simple, high } \\
\text { pressure }\end{array}$ & $100^{\circ} \mathrm{C}$-high & $\begin{array}{l}\text { Hours/ } \\
\text { days }\end{array}$ & Medium & $\begin{array}{l}\text { Needed, } \\
\text { during } \\
\text { reaction }\end{array}$ \\
\hline
\end{tabular}

Table 1. Comparison of different synthetic methods to produce MNPs.

Particles prepared by co-precipitation unfortunately tend to be rather polydisperse as indicated in the Fig. 1a. It is well known that a short burst of nucleation and subsequent slowly controlled growth is crucial to produce monodisperse particles. Controlling these processes is therefore the key in the production of monodisperse iron oxide MNPs. In order to prevent them from possible oxidation in air as well as from NPs agglomeration, coprecipitated NPs are usually coated with organic or inorganic molecules during the precipitation process. Recently, significant advances in preparing monodisperse magnetite NPs, of different sizes, have been made by the use of organic additives as stabilizing and/or reducing agents. The NP preparation can be achieved in presence of stabilizing agents such as dextran, polyvinyl alcohol, citrate, polyethyleneimine, block copolymers, and using various silane-based chemistry (Majewski \& Thierry, 2007). Recent studies also showed that oleic acid is the best candidate for the stabilization of $\mathrm{Fe}_{3} \mathrm{O}_{4}$ (Cushing et al., 2004; Willis et al., 2005). The effect of organic ions on the formation of metal oxides or oxyhydroxides can be rationalized by two competing mechanisms. Chelation of the metal ions can prevent nucleation and lead to the formation of larger particles because the number of nuclei formed is small and the system is dominated by particle growth. However, the adsorption of additives on the nuclei and the growing crystals may inhibit the growth of the particles, which favors the formation of small units.

On the other hand, better control over size, monodispersity and shape can be achieved using emulsions, microemulsion $(\mu e)$ or nanoemulsion $(n e)$ systems (water-in-oil or oil-in-water) that provide a confined environment during nucleation and growth of the iron oxide NPs (Gupta \& Wells, 2004). In practice, however, little control can actually be driven over the size 
and size distribution of the nanostructures and, moreover, only small quantities of iron oxide can be obtained, owing to the constraints of low reagent amount required by this synthetic procedure. A $\mu$ is defined as a thermodynamically stable isotropic dispersion of two immiscible liquids, since the microdomain of either or both liquids has been stabilized by an interfacial film of surface-active agents. In water-in-oil $\mu$, the aqueous phase is dispersed as microdroplets (typically $1-50 \mathrm{~nm}$ in size) surrounded by a monolayer of surfactant molecules in the continuous hydrocarbon phase. The size of the reverse micelle is determined by the molar ratio of water to surfactant. When a soluble metal salt is incorporated in the aqueous phase of the $\mu$, it will remain in the aqueous microdroplets surrounded by oil. By mixing two identical water-in-oil $\mu e$ containing the desired reactants, these microdroplets will continuously collide, coalesce, and break again (Malheiro et al., 2007). By the addition of solvent, such as acetone or ethanol to the $\mu e$, the precipitate can be extracted by filtering or centrifuging the mixture. In this sense, a $\mu e$ can be used as a nanoreactor for the formation of NPs. Using the $\mu$ e technique, metallic NPs and alloys (Co, $\mathrm{Fe}, \mathrm{FeCo}, \mathrm{FePt}, \mathrm{CoPt}$, etc.) or magnetic oxide such as iron oxide or spinel ferrites, $\mathrm{MFe}_{2} \mathrm{O}_{4}(\mathrm{M}$ : $\mathrm{Mn}, \mathrm{Co}, \mathrm{Ni}, \mathrm{Cu}, \mathrm{Zn}, \mathrm{Mg}$, or $\mathrm{Cd}$, etc.) have been synthesized in reverse micelles (water in oil systems) by using many different surfactants and co-surfactants molecules (O'Connor et al., 1999). Co-surfactant molecules, generally an alcohol with small chain, have an important role in the reverse micelle structure formation increasing the molecules density onto the $\mu e$ threshold and avoiding the metallic cations percolation (Malheiro et al., 2007). For example, highly monodispersed iron oxide NPs were synthesized by using the aqueous core of aerosol-OT (AOT)/n-hexane reverse micelles (w/o $\mu$ ) as showed in Fig. 1b. The reverse micelles have aqueous inner core, which can dissolve hydrophilic compounds, salts, etc. A deoxygenated aqueous solution of the $\mathrm{Fe}^{3+}$ and $\mathrm{Fe}^{2+}$ salts (molar ratio 2:1) was dissolved in the aqueous core of the reverse micelles formed by AOT in $n$-hexane. Chemical precipitation was achieved by using a deoxygenated solution of sodium hydroxide. Smaller and more uniform particles were prepared by precipitation of magnetite at low temperature in the presence of nitrogen gas. As described in the conventionally $\mu$ preparation methods, two identical $\mu e$ systems are mixed and coalesced. During coalescence stage, the microdroplet size was continuously varying while the aqueous solution mixture becomes reacting and the initial nucleation step took place. Thus, although many types of MNPs have been synthesized in a controlled manner using the $\mu$ method, the particle size and shapes usually vary over a relative wide range. This problem have been solved by using a cationsubstituted surfactant molecules in which the polar head containing the desired cation and the aqueous solution was formed by second reactant, such as the alkaline. In this way, the coalescence stage is avoided and the microdroplet size control is more effective. Moreover, the working window for the synthesis in $\mu$ is usually quite narrow and the yield of NPs is low compared to other methods, such as thermal decomposition and co-precipitation. Large amounts of solvent are necessary to synthesize appreciable amounts of material. It is thus not a very feasible process and also rather difficult to scale-up.

Inspired by the synthesis of high-quality semiconductor nanocrystals and oxides in nonaqueous media by thermal decomposition ( $\mathrm{Lu}$ et al., 2007; O'Brien et al., 2001), the most promising method for the synthesis of MNPs with control over size and shape have been developed to date. Monodisperse magnetic nanocrystals with smaller size can essentially be synthesized through the thermal decomposition of organometallic compounds in highboiling organic solvents containing stabilizing surfactants with long chain carboxylic acids and amines (Hyeon, 2003a; Sun et al., 2000; Varanda \& Jafelicci, 2006). The organometallic 
precursors include metal acetylacetonates, metal cupferronates or carbonyls. The reagent proportions, reaction temperature, reaction time, as well as aging period are crucial for the precise control of size and morphology. If the metal in the precursor is zero-valent, such as in carbonyls, thermal decomposition initially leads to formation of the metal, but two-step procedures can be used to produce oxide NPs. For instance, iron pentacarbonyl can be decomposed in a mixture of octylether and oleic acid with subsequent addition of trimethylamine oxide $\left(\mathrm{CH}_{3}\right)_{3} \mathrm{NO}$ as a mild oxidant at elevated temperature, results in formation of monodisperse $\gamma-\mathrm{Fe}_{2} \mathrm{O}_{3}$ nanocrystals with a size of approximately $13 \mathrm{~nm}$ (Hyeon et al., 2001). Decomposition of precursors with cationic metal centers leads directly to the oxides, that is, to $\mathrm{Fe}_{3} \mathrm{O}_{4}$, if [ $\left.\mathrm{Fe}(\mathrm{acac})_{3}\right]$ is decomposed in the presence of 1,2- hexadecanediol, oleylamine, and oleic acid in phenylether, as showed in Fig. 1c. The size and shape of the nanocrystals could be controlled by variation of the reactivity and concentration of the precursors. The reactivity was tuned by changing the chain length and concentration of the surfactants. Generally, the shorter the chain length, the faster the reaction rate is. Alcohols or primary amines could be used to accelerate the reaction rate and lower the reaction temperature. Hyeon et al. (Park et al., 2004) have also used a similar thermal decomposition approach for the preparation of monodisperse iron oxide NPs. They used nontoxic and inexpensive iron(III) chloride and sodium oleate to generate an iron oleate complex in situ which was then decomposed at high temperatures in different solvents, such as 1hexadecene, octylether, 1-octadecene, 1-eicosene, or trioctylamine. Particle sizes are in the range of 5-22 nm, depending on the decomposition temperature and aging period. The NPs obtained are dispersible in various organic solvents including hexane and toluene. However, water soluble MNPs are more desirable for applications in biotechnology. For that purpose, a very simple synthesis of water-soluble magnetite NPs was reported recently. Using $\mathrm{FeCl}_{3} \cdot 6 \mathrm{H}_{2} \mathrm{O}$ as iron source and 2-pyrrolidone as coordinating solvent, water soluble $\mathrm{Fe}_{3} \mathrm{O}_{4}$ nanocrystals were prepared under reflux $\left(245^{\circ} \mathrm{C}\right)(\mathrm{Li}$ et al., 2005). The mean particles size can be controlled at 4,12, and $60 \mathrm{~nm}$, respectively, when the reflux time is 1, 10, and 24 h. With increasing reflux time, the shapes of the particles changed from spherical at early stage to cubic morphologies for longer times. More recently, the same group developed a one-pot synthesis of water-soluble magnetite NPs prepared under similar reaction conditions by the addition of a dicarboxyl-terminated poly(ethylene glycol) as a surface capping agent (Hu et al., 2006). These NPs can potentially be used as magnetic resonance imaging contrast agents for cancer diagnosis. The thermal decomposition method is also used to prepare metallic NPs (Varanda et al., 2007; Varanda \& Jafelicci, 2006). The advantage of metallic NPs is their larger magnetization compared to metal oxides. Metallic iron, cobalt, nickel and alloys such as FePt (Fig. 1d), CoPt, NiPt, and CrPt or using Ru instead Pt in the alloys NPs were synthesized by thermal decomposition of different metallic precursors in a varied of solvents. Magnetic alloys have many advantages, such as high magnetic anisotropy, enhanced magnetic susceptibility, and large coercivities. Beside $\mathrm{CoPt}_{3}$ and $\mathrm{FePt}$, metal phosphides are currently of great scientific interest in materials science and chemistry. For example, hexagonal iron phosphide and related materials have been intensively studied for their ferromagnetism, magnetoresistance, and magnetocaloric effects (Luo et al., 2004). In addition, the thermal decomposition method can be used to synthesized antiferromagnetic NPs such as $\mathrm{MnO}$ (Fig. 1e) and $\mathrm{FeO}$ which have been waking is very interesting due to potential application in MRI as water relaxation time $\mathrm{T}_{2}$ interfering. Due to their versatility, the thermal decomposition method has been also combining with the seed-mediated growth methodology in order to synthesis core-shell nanosctrutuctured NPs such as $\mathrm{Fe}_{3} \mathrm{O}_{4}$-coated $\mathrm{FePt}\left(\mathrm{FePt} @ \mathrm{Fe}_{3} \mathrm{O}_{4}\right.$, Fig. 1f) (Varanda et al., 2008). 


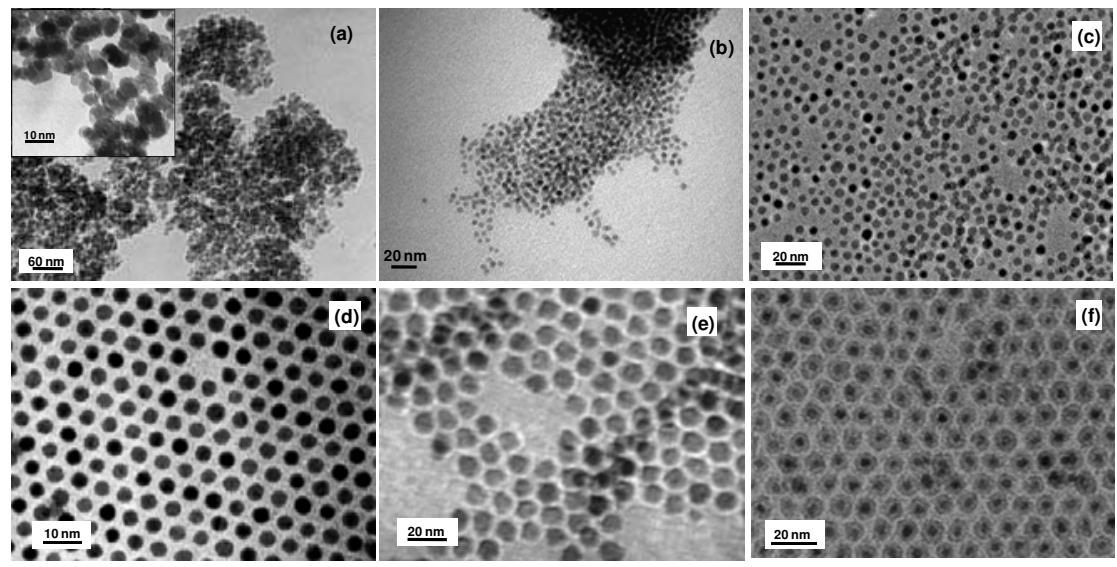

Fig. 1. TEM of MNPs prepared using different synthetic routes: above, magnetite synthesized by (a) co-precipitation, (b) microemulsion, and (c) thermal decomposition; bellow, (d) FePt, (e) $\mathrm{MnO}$, and (f) $\mathrm{FePt}_{\mathrm{F}} \mathrm{Fe}_{3} \mathrm{O}_{4}$ synthesized by thermal decomposition.

\section{Surface engineering}

The functionalization of NP surface is one method for tuning the overall properties of particles to fit targeted applications. The surface modification of NPs by functional molecules/particles/polymers has different tasks to fulfill (de Dios \& Díaz-Garcia, 2010):

a. stabilize the NPs in solution to control the growth of the embryonic particles and determine their shape during the growth process;

b. provide functional groups at the surface for further derivatization;

c. enhance NP solubilization in various solvents extending their application possibilities;

d. capping layers can modify the electronic, optical, magnetic and chemical properties of the particles, providing a plethora of controllable nanotools;

e. modify the capability to assemble the particles in specific arrays or the ability to target desired chemical, physical, or biological environments;

f. improve mechanical and chemical performances of the NP surface, e.g. passivation;

g. in some instances a reduction of their toxicity is achieved.

Colloidal nanostructures dispersed in a medium collide with each other frequently and the overall colloidal stability of the dispersion, which is critical to most potential NP applications, is dictated by the fate of the individual particles after each collision (Hunter, 2001). Attractive interactions leads to irreversible aggregation of the NPs, and in the case of magnetite particles, magnetic dipole-dipole interactions can provide an additional attractive force. A critical requirement is therefore to surface-engineer the NPs with (macro) molecules that provide repulsive forces large enough to counter the attractive ones in the collision processes. Repulsive forces can be achieved in the presence of an electrical double layer on the particles (electrostatic stabilization) or in presence of polymeric chains providing steric stabilization. Attractive van der Waals and repulsive Coulombian forces are strongly influenced by the dispersion medium properties. Colloidal stability of NP dispersion must therefore be considered for a specific system, especially in the setting of bio-applications that require colloidal stability in complex biological medium such as blood or plasma. Steric 
stabilization provided by adsorption or grafting of polymers on the NPs is the most efficient way to prevent aggregation in bio-systems (Majewski \& Thierry, 2007).

Biomedical applications often require stringent control of the NPs bio-interfaces. Along with the need for colloidal stability in complex biological environment, a major requirement for the successful integration of MNPs in biomedical application is indeed to minimize biologically non-specific adsorption events, for example, the adsorption of plasma proteins on the NP surfaces. Such non-specific events can drastically hamper molecular recognition processes at the surface of the NPs, therefore reducing the efficiency of MNP-based bioassays. A pre-requisite to the widespread use of NPs in vivo is also their ability to resist nonspecific adsorption of opsonins. Opsonization of NPs by plasma proteins results into rapid elimination from the blood by the mononuclear phagocyte system (MPS) with consequent accumulation in organs of the reticuloendothelial system (RES, phagocytic cells residing in tissues forming party of the body immune system) such as spleen and liver. The nature (e.g., complement proteins and immunoglobulins) and amount of plasma proteins adsorbing on NPs is directly related to the physicochemical characteristics of the NPs surfaces. Adsorbed opsonins potentially lead to specific interactions with receptors on the surface of macrophages and hepatocytes and the subsequent elimination of the NPs (Vonarbourg et al., 2006; Yan et al., 2005). For instance, concerning NP sizes, for example, the overall particle size must be small enough to evade uptake by the RES, but large enough to avoid renal clearance. Procedures to achieve high quality bio-interfaces able to resist non-specific interaction have been implemented on macroscopic surfaces. It is commonly admitted that non-fouling surfaces should posses the following characteristic: (1) hydrophilic, (2) hydrogen bond acceptors, (3) no hydrogen bond donors, (4) neutral. In summary, colloidal electrostatic stabilization arising from repulsion of surface charges on the NPs is typically not adequate to prevent aggregation in biological solutions due to the presence of salts or other electrolytes that may neutralize this charge. Furthermore, upon intravenous injection the surfaces of MNPs are subjected to adsorption of plasma protein, or opsonization, as the first step in their clearance by the RES. Evading uptake by the RES and maintaining a long plasma half-life is a major challenge for many MNP applications in medicine (Berry \& Curtis, 2003; Sun et al., 2008). In order to minimize these critical effects, besides other considerations such as toxicity, biodistribution, and blood circulation time (see Section 7), many coating process have been used to modify/functionalize the NP surfaces, that provide a biocompatible surface, and after properly derivatization with targeting ligands, a bioselectable surface for an specific body tissue, as schematically represented in the Fig. 2.

\subsection{Polymeric coatings}

Polymeric coatings provide a steric barrier to prevent NP agglomeration and avoid opsonization. These coatings also provide a means to tailor the surface properties of MNPs such as surface charge and chemical functionality. Some critical aspects with regard to polymeric coatings may affect the MNP performance including nature of the polymer chemical structure (e.g. hydrophilicity/hydrophobicity, biodegradation characteristics, etc.), the length or molecular weight of the polymer, the manner in which the polymer is anchored or attached (e.g. electrostatic or covalent bonding), the conformation of the polymer, and the degree of particle surface coverage. Various monomeric species, such as bisphosphonates, dimercaptosuccinic acid, and alkoxysilanes, have been evaluated as anchors to facilitate attachment of polymer coatings on MNPs (Sun et al., 2008). 


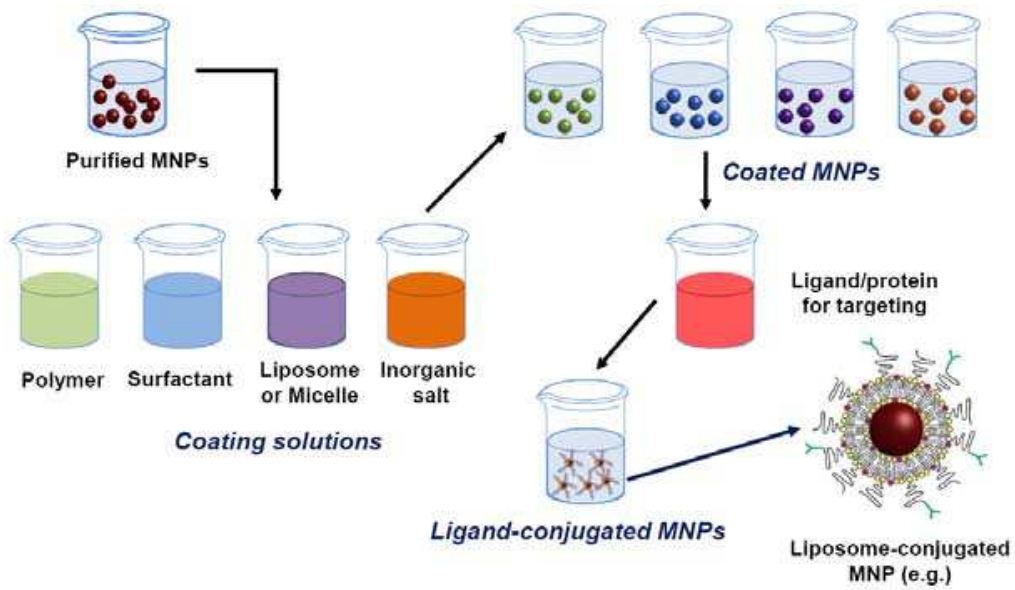

Fig. 2. Representative MNPs surface engineering coating process using polymer, surfactant, liposome, and inorganic salt (core-shell nanostructure) followed by derivatization surface with targeting ligands (biocompatible and biosselective MNPs for biomedical applications).

The molecular weight and geometric orientation of the polymer on the surface of the particles in the form of loops, trains, and tails or as end-grafted brushes or as fully encapsulated polymer shells not only affect the antifouling characteristics of the NP, but also contribute to their effective hydrodynamic size, which is another key factor in avoiding recognition by the RES. A variety of natural and synthetic polymers have been evaluated for use as coatings on MNPs. Readers are directed to several reviews on the topic for a comprehensive analysis of these materials (Gupta et al., 2007; Gupta \& Gupta, 2005). In this section the most widely utilized and successful polymer coating for in vivo applications will be emphasized. Among several nature and synthetic polymers used as coating in MNPs for biomedical applications, many monomers due to systematic uses can be mentioned: (a) dextran, biocompatible and biodegradable, may be administered by an intravenous or oral route and used to stabilizer the colloidal solution and enhancer the blood circulation time (Massia et al., 2000). Dextran coatings can be achieved directly during the preparation of magnetite NPs in the co-precipitation technique but also by conjugating reactive dextran, for example, carboxymethyl dextran and partially oxidized dextran (via formation of Schiff's bases linkages), onto functionalized NPs. The nature of the dextran derivative, the number of reactive groups and immobilization conditions (e.g., ionic strength, $\mathrm{pH}$ ) can be used to control the final polymer conformation on the surfaces (Majewski \& Thierry, 2007). As mentioned earlier, an issue when working with NPs is to avoid irreversible aggregation during coating procedures subsequent to synthesis. Optimizing experimental conjugation conditions, monodisperse carboxymethyl dextran-coated monocrystalline magnetite NPs prepared by microemulsion methodology have been prepared without detectable aggregation; (b) poly(ethylene glycol), PEG, is another widely used polymer for NP coating owing to its hydrophilicity and no-antigenic and no-immunogenic properties (Brus et al., 2004; Gupta et al., 2007). The antifouling nature of PEG has been shown to reduce NP uptake by macrophages and extend blood circulation time in vivo. Various methods have been utilized to attach PEG to MNPs including silane grafting to oxide surfaces, polymerization at the surface of MNPs, and modification through sol-gel approaches 
(Gupta et al., 2007). To control polymer conformation and provide stable covalent linkages to the surface of iron oxide NPs, Kohler et al. developed bifunctional PEG silanes capable of forming self-assembled monolayers (SAMs) and increasing the packing density of the polymer chains onto the NPs surface (Kohler et al., 2004; Zhang et al., 2002). In addition, terminal amine or carboxyl groups extending out from the NP surface provide sites for conjugation of functional ligands, as demonstrated by the attachment of folic acid. The strong attachment of the PEG molecules not only improved the steric stabilization of the MNPs in vivo against interactions with opsonins and cells, but also imparts the prolonged circulation in blood and reduced RES uptake (Gupta \& Curtis, 2004; Gupta \& Wells, 2004). In addition, PEG-coated MNPs are hugely internalized by cells, presumably owing to the fluid phase endocytosis mechanism, probably their high solubility in cell membranes, since it is an amphiphilic molecule; (c) polyvinyl alcohol (PVA) is used to prevent agglomeration and enhancing the colloidal stability (Xue \& Sun, 2001); (d) polyacrylic acid (PAA) increase the stability and biocompatibility of the NP and also helps in bioadhesion (Burugapalli et al., 2004). Another consideration to take into account while utilizing polymer coatings is their effects on the NP magnetic properties, where the saturation magnetization generally decreases with the thickness polymer coating increases (Mikhaylova et al., 2004).

\subsection{Non-polymeric stabilizers (surfactants)}

Surfactants or polymers are often employed to passivate the surface of the NPs during or after the synthesis to avoid agglomeration. In general, electrostatic repulsion or steric repulsion can be used to disperse NPs and keep them in a stable colloidal state. In the case of ferrofluids, the surface properties of the magnetic particles are the main factors determining colloidal stability. The major measures used to enhance the stability of ferrofluids are the control of surface charge and the use of specific surfactants ( $\mathrm{Lu}$ et al., 2007). For instance, magnetite NPs synthesized through the co-precipitation of $\mathrm{Fe}^{2+}$ and $\mathrm{Fe}^{3+}$ in ammonia or $\mathrm{NaOH}$ solution are usually negatively charged, resulting in agglomeration. In general, surfactants can be chemically anchored or physically adsorbed on MNPs to form a single or double layer which creates repulsive (mainly as steric repulsion) forces to balance the magnetic and the van der Waals attractive forces acting on the NPs. Thus, by steric repulsion, the magnetic particles are stabilized in suspension. Additionally, in order to stabilize the colloidal dispersion, Gedanken et al. studied the adsorption of alkanesulphonic and alkanephosphonic acids on the surfaces of amorphous $\mathrm{Fe}_{2} \mathrm{O}_{3} \mathrm{NPs}$ and proposed two possible bonding schemes for the phosphonate ions on $\mathrm{Fe}^{3+}$, i.e., one $\mathrm{O}$ or two $\mathrm{O}$ atoms of the phosphonate groups binding onto the surface (Yee et al., 1999). Sahoo et al. have reported the surface derivatization of magnetite by oleic acid, lauric acid, dodecylphosphonic acid, hexadecylphosphonic acid, dihexadecylphosphonic acid etc. to stabilize the NPs in organic solvents (Sahoo et al., 2001). They found that alkyl phosphonates and phosphates could be used for obtaining thermodynamically stable dispersions of MNPs. The authors suggested on the basis of the results obtained from the temperature and enthalpy desorption studies that these ligands form a quasi-bilayer structure with the primary layer strongly bonded to the surface of NPs. The ferrofluids, frequently dispersed in hexadecane as the carrier medium, may be stabilized by various long-chain surfactants, the classic example being oleic acid, which has a C18 (oleic) tail with a cis-double-bond in the middle, forming a kink. Such kinks have been postulated as necessary for effective stabilization, and indeed stearic acid, with no double-bond in its C18 (stearic) tail, cannot stabilize ferrofluid suspensions (Gupta 
\& Gupta, 2005). The long chain surfactants uses such as oleic acid and oleylamine, generally employed in the thermal decomposition synthesis, leads too much stabilized NPs suspension in organic media (e.g. hexane), but is desired water stabilized NPs suspension for biomedical applications. In this cases, ligand exchanges or coating with water compatible molecules/compounds can be use to stabilizer these NPs in water suspension instead organic solvents. Because use of polymers leads to thick surface layers, Portet et al. have (Portet et al., 2001) developed monomeric organic molecules as coating materials. The main property of these small molecules is to produce a homogeneous coating of the entire iron oxide core that is able to inhibit the protein absorption. Phosphorylcholine (PC)-derived polymers are known to protect prosthesis against protein contamination, but pure PC coatings do not allow colloidal stability at physiological pH (Denizot et al., 1999).

\subsection{Liposomes and micelles}

The development of liposomes as drug delivery vehicles can be considered one of the earliest forms of nanomedicine recently developed. These phospholipid bi-layered membrane vesicles, as indicated in the Fig. 2, can range from $100 \mathrm{~nm}$ up to $5 \mu \mathrm{m}$ in size and have been utilized for the delivery of small molecules, proteins and peptides, DNA, and MR imaging contrast agents (Sun et al., 2008; Torchilin, 2005). An advantage of liposome encapsulation or micelar nanoparticle environment (MNE) is that it in vivo behavior already has been well established with processes such as PEGylation resulting in long circulation times. Another favorable feature of liposomes is the ability to encapsulate a large number of MNP cores and deliver them together, avoiding dilution, to a target site. Combining a therapeutic agent in the payload further enhances the multifunctionality of these delivery vehicles. Magnetic fluid-loaded liposomes (MFLs) with hydrodynamic size of $195 \pm 33 \mathrm{~nm}$ were formed by film hydration coupled with sequential extrusion and were capable of encapsulating up to $1.67 \mathrm{~mol}$ of iron per mol of lipid. In vivo evaluation in mice using MR angiography demonstrated that these MFLs were still present in the blood $24 \mathrm{~h}$ after intravenous injection confirming their long circulating behavior. Similarly, multifunctional micelles formed with amphiphilic block copolymers have also been used to entrap MNPs for these applications (Sutton et al., 2007). Many micelar system mainly based on the phospholipid or phospholipid-derivated have been studying in order their potential application in drug delivery system and, in addition, their biocompatible properties has used as coating system in order to promote the MNP increases blood circulation, biodistribution and cell membrane internalization.

\subsection{Inorganic coating (core-shell nanostructure)}

In addition to organic coatings, core-shell structures utilizing biocompatible silica, gold or other noble metal, carbon, etc., to encapsulate the MNPs have become another attractive approach for developing MNPs for biomedical applications. These NPs have inner iron oxide/alloys magnetic core with an outer metallic shell of inorganic materials. These inert coatings, or shells, provide not only the stability to the NPs in solution but also protection against chemical degradation of magnetic cores, prevent the release of potentially toxic components, and helps in binging the many biological ligands at the NP surface since that functionalization chemistries are generally better established with these materials than those that comprise MNPs. Silica shells are attractive options to serve as protective coatings on MNPs due to their stability under aqueous conditions and ease of synthesis. An advantage 
of having a surface enriched in silica is the presence of surface silanol groups that can easily react with alcohols and silane coupling agents to produce dispersions that are not only stable in non-aqueous solvents but also provide the ideal anchorage for covalent bounding of specific ligands. The strong binding makes desorption of these ligands a difficult task. In addition, the silica surface confers high stability to suspensions of the particles at high volume fractions, changes in $\mathrm{pH}$ or electrolyte concentration (Gupta \& Gupta, 2005). Thus, a silica shell does not only protect the magnetic core, but can also prevent the direct contact of the core with additional agents linked to the silica surface avoiding unwanted interactions. Sol-gel processes using tetraethoxysilane (TEOS) are generally utilized throughout the literature to produce coatings of controlled thickness (Lu et al., 2002). The use of functional alkoxysilanes, such as 3-aminopropyltriethyoxysilane (APS), allows for surface reactive groups to be easily added to these core-shell structures. In addition, the ability to encapsulate functional molecules, such as alternative imaging or therapeutic agents, within this protective matrix is a unique feature to these nanostructures (Tada et al., 2007).

The Stöber method and sol-gel processes are the prevailing choices for coating MNPs with silica. The coating thickness can be tuned by varying the concentration of ammonium and the ratio of TEOS to $\mathrm{H}_{2} \mathrm{O}$. The functionalization could introduce additional functionality, so that the magnetic particles are potentially of use in biolabeling, drug targeting, and drug delivery. In previous studies involving the coating of hematite spindles and much smaller magnetite clusters with silica, the iron oxide cores could subsequently be reduced in the dry state to metallic iron (Varanda et al., 2002a; Varanda et al., 2001). The advantage of this method is that silica coating was performed on an oxide surface, which easily binds to silica through $\mathrm{OH}$ surface groups. Since the iron oxide surface has a strong affinity towards silica, no primer was required to promote the deposition and adhesion of silica. Owing to the negative charges on the silica shells, these coated MNPs are re-dispersible in water without the need of adding other surfactants. Though great progress in the field of silica-coated NPs has been made, the synthesis of uniform silica shells with controlled thickness on the nanometer scale still remains challenging. As an alternative, the microemulsion method was also tried resulting in a best silica thickness control. Although metals protected by silica can be synthesized by reduction after synthesis, silica deposition directly on pure metal particles is more complicated because of the lack of $\mathrm{OH}$ groups on the metal surface. An additional difficulty for coating metallic NPs, such as iron and cobalt with silica, which has to be overcome, is that iron and cobalt are readily oxidized in the presence of dissolved oxygen. Therefore, it is necessary to use a primer to make the surface "vitreophilic" (glasslike), such as coat precious metals or realize the metal surface passivation by the gentle oxidation as starting materials for such silica coating. From the mentioned examples above, it can be seen that silica coating of magnetic oxide NPs is a fairly controllable process. However, silica is unstable under basic condition, in addition, silica may contain pores through which oxygen or other species could diffuse. Coating with other oxides is much less developed and therefore alternative methods, especially those which would allow stabilization under alkaline conditions, are needed. Gold offers several advantages as a coating material for MNPs due to its low chemical reactivity and unique ability to form self-assembled monolayers (SAMs) on their surface using alkanethiols (Sun et al., 2008). Unfortunately, this chemical inertness may also lead to difficulty in forming gold shells over MNPs. Recent advances in synthesizing gold-coated iron NPs through a variety of methods ranging from reversed microemulsion, combined wet chemical, to laser irradiation, redox transmetalation, iterative hydroxylamine seeding, have been reviewed by $\mathrm{Lu}$ et al. (Lu et al., 2007). Gold 
coating of MNPs is especially interesting, since the gold surface can be further functionalized with thiol groups. This treatment allows the linkage of functional ligands which may make the materials suitable for catalytic and optical applications. Although to date most studies have focused on the development of polymer or silica protective coatings, recently carbon-protected MNPs are receiving more attention, because carbon-based materials have many advantages over polymer or silica, such as much higher chemical and thermal stability as well as biocompatibility. Since then, many studies have shown that in the presence of metal NPs, graphitized carbon structures, such as carbon nanotubes and carbon onions, are formed under arc-discharge, laser ablation, and electron irradiation. The well-developed graphitic carbon layers provide an effective barrier against oxidation and acid erosion. These facts indicate that it is possible to synthesize carbon-coated MNPs, which are thermally stabile and have high stability against oxidation and acid leaching, which is crucial for some applications (Lu et al., 2007).

\section{Multifunctional magnetic nanoparticles}

Despite the potential benefits that MNPs have rendered to biomedicine, some applications remains challenging, for instance, in vivo real-time monitoring of cellular events, specific targeting to the action site or efficient drug delivery inside the target cell. In this context, the design of multifunctional NPs could significantly improve already existing NPs characteristics and help to surmount these challengers. Whereas a monofunctional NP provide a single function, i.e. a liposome can transport drugs but does not have the inherent property to distinguish between healthy and unhealthy cells or tissues, a multifunctional NPs combine different functionalities in a single stable construct. For example, a core particle could be linked to a specific targeting function that recognizes the unique surface signatures of their target cells. Simultaneously, the same particle can be modified with an imaging agent to monitor the drug transport process, a function to evaluate the therapeutic efficacy of a drug, a specific cellular penetration moiety and a therapeutic agent (Sanvicens \& Marco, 2008). Thus, the fabrication of bifunctional or multifunctional NPs has received a great deal of attention in recent years. Hybrid inorganic NPs are emerging as useful probes for magnetic-based targeting, delivery, cell separation, MRI, and fluorescence-based biolabeling applications. Gold ( $\mathrm{Au}) \mathrm{NPs}$ have been extensively used to prepare multifunctional composites with quantum dots (QDs) and MNPs. Typical examples include $\mathrm{Fe}_{3} \mathrm{O}_{4}-\mathrm{Au}$ (Yu et al., 2005), CdSe-Au (Mokari et al., 2004), and PbSe-Au-Fe $\mathrm{O}_{4}$ (Shi et al., 2006). Multifunctional NPs have been actively explored for the enhancement of imaging, targeting, and delivery. In the field of biological and biomedical imaging, QDs and MNPs have been enjoying greater roles in biolabeling and MRI respectively. A combination of optical and magnetic properties in a single material would enable simultaneous biolabeling/imaging and cell sorting/separation. Nanocomposites consisting of semiconductor and MNPs, known as magnetic quantum dots (MQDs) or luminomagnetic nanoparticles (LMNPs) (Sun et al., 2008), are of great interest as a new class of materials (Selvan et al., 2010). Despite all of these advances, the application of multifunctional NPs in in vivo imaging is still in its infancy. As discussed throughout this Chapter, the ability to add components to MNPs in a modular fashion allows for specific features and functional moieties to be interchanged or combined. Ligands such as targeting agents, permeation enhancers, optical dyes, and therapeutic agents can all be conjugated on the surface or incorporated within these nanostructures (Fig. 3, left). 

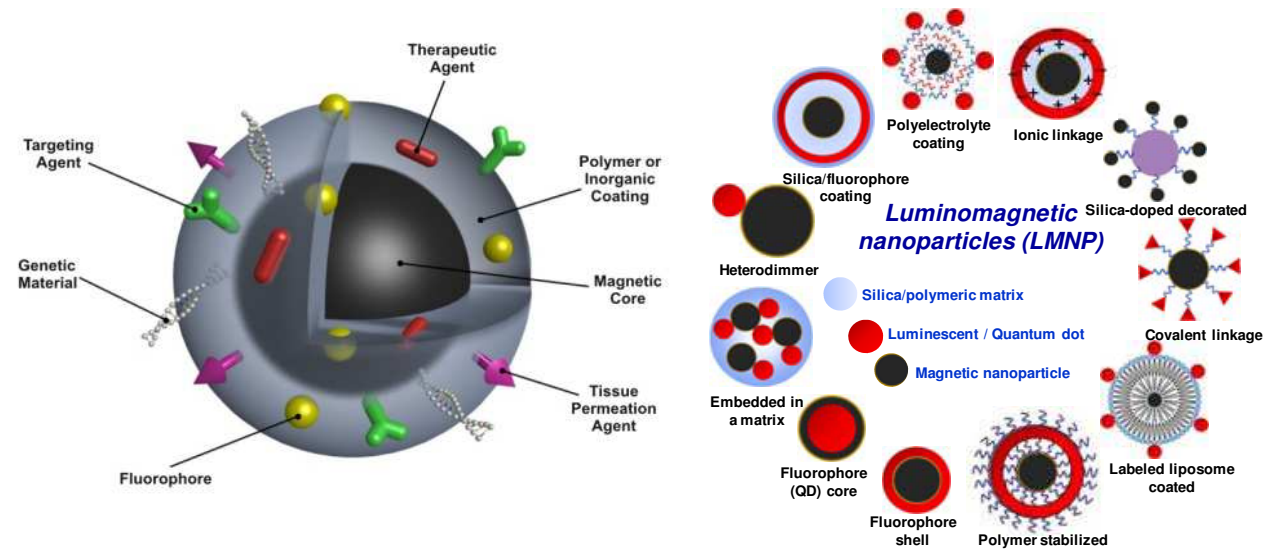

Fig. 3. (left) Targeting, therapeutic, luminescent and biocompatibility agents on the same NP surface enabling multifunctionality in a single MFMNP; (right, adapted from (Corr et al., 2008) Many different types of LMNPs according to their preparation route.

To perform such nanoscale engineering, bioconjugation chemistries and techniques utilized for protein coupling have been studied (Sun et al., 2008). Techniques such as avidin-biotin binding, use of heterobifunctional linkers to form amide, ester, or disulfide bonds, and more recently "click" chemistries (Nandivada et al., 2007), have all been shown to be useful in attaching functional ligands to MNPs. In addition to understanding the mechanisms of these reactions, those utilizing these techniques on MNPs may also find it useful to review basic concepts of colloidal science to avoid unwanted NP flocculation or aggregation (Hunter, 2001). One example of adding functionality to MNPs has been the combination of organic dyes or fluorophores as optical agents allowing detection by multiple imaging modalities.

Both magnetic and fluorescent inorganic NPs have been shown to play a significant role in nanotechnology. Just looking at the wealth of possible applications open to magnetic and fluorescent materials, it is not hard to see why the combination of these two entities opens up the opportunity to provide new nanocomposites which could act as multi-targeting, multi-functional and multi-treating tools. It is expected that the combination of magnetic and fluorescent properties in one nanocomposite would open up great prospects both in nano- and biotechnology, enabling the engineering of unique targeted, nanoscale photonic devices which could be manipulated using an external magnetic field. The combination of a magnetic and a fluorescent entity in a new bimodal "two-in-one" LMNP may provide a new multifunctional nanomaterial with a broad range of potential applications. First of all, multimodal magnetic-fluorescent assays would be very beneficial for in vitro and in vivo bioimaging applications such as MRI and fluorescence microscopy. Second of all, these nanocomposites can be utilized as agents in nanomedicine. For example, one of their most promising applications is a bimodal anticancer therapy, encompassing photodynamic and hyperthermic capabilities. LMNPs can also serve as an all-in-one diagnostic and therapeutic tool, which could be used, for example, to visualize and simultaneously treat various diseases. Another exciting application of LMNPs is in cell tracking, cytometry and magnetic separation, which could be easily controlled and monitored using fluorescent microscopy. A specific difficulty in the preparation of two-in-one LMNPs is the risk of quenching of the fluorophore on the surface of the particle by the magnetic core. In addition, if there are a 
number of fluorescent molecules attached to the surface of the particle, they may act to quench each other. The problem of quenching can be partially resolved by providing the MNP with a stable shell prior to the introduction of the fluorescent molecule, or by first treating the fluorophore with an appropriate spacer. Finally there are typical problems related to instability and aggregation of the nanocomposites in solutions. Therefore, a careful design and an extremely accurate synthesis methodology are required for the development of the LMNPs to avoid their aggregation and precipitation in comparison to the developed techniques used in the case of MNPs. Most of these nanocomposites are coreshell nanostructures. In general, we can identify eight main types of LMNPs (Fig. 3, right) (Corr et al., 2008). Recently, the conjugation of near-infrared fluorescent (NIRF) dyes to MNPs has received significant attention due to the deep penetration of NIRF light through tissues. The integration of NIRF detectability may allow for these NPs to be used for both presurgical planning by MRI and intraoperative resection of malignant tissues by optical imaging. Since both MRI and optical signals come from the same NPs, the MR image can serve as a roadmap to the fluorescently labeled tumor cells (Sun et al., 2008).

\section{Biomedical applications of nanomagnetics}

\subsection{Magnetic resonance imaging - MRI}

MRI is one of the most powerful imaging techniques for living organisms as it provides images with excellent anatomical details based on soft-tissue contrast and functional information in a non-invasive and real-time monitoring manner. MRI has further advanced by the development of contrast agents that enable more specific and clearer images and enlargements of detectable organs and systems, leading to a wide scope of applications of MRI not only for diagnostic radiology but also for therapeutic medicine. Current MRI contrast agents are in the form of either paramagnetic complexes or MNPs. Paramagnetic complexes, which are usually gadolinium $\left(\mathrm{Gd}^{3+}\right)$ or manganese $\left(\mathrm{Mn}^{2+}\right)$ chelates, accelerate longitudinal $\left(\mathrm{T}_{1}\right)$ relaxation of water protons and exert bright contrast in regions where the complexes localize. For instance, gadolinium diethylenetriamine pentaacetate (Gd-DTPA) has been the most widely used of such complexes and its main clinical applications are focused on detecting the breakage of the blood-brain barrier (BBB) and changes in vascularity, flow dynamics, and perfusion (Na et al., 2007; Weinmann et al., 2003). Iron oxide NPs were the first, and are the most commonly used MNP-based contrast agents for MRI. Importantly, it have been taken through regulatory approval and may be safety, and legally, used in human (Pankhurst et al., 2009). The limitations of using MNPs, however, are that millions of particle with very high saturation magnetization values are required to achieve sufficient contrast (Gupta et al., 2007). The efficacy, as MRI contrast agent, of iron oxide NPs depends to a large extent on their physicochemical properties, particularly their size and surface chemistry, the later properly bioconjugated with targeting agents. The spinspin relaxation time $\left(\mathrm{T}_{2}\right)$ depends of the MNP size and larger particles exhibit larger $\mathrm{T}_{2}$ effect (Bin Na et al., 2007). In addition, the intrinsic magnetization of the particles is also important and metallic or alloys NPs are preferable than iron oxides concerning the Ms of these latter. In this context, cobalt NPs present much higher room temperature Ms than those iron oxides, which could be resulting in a larger effect on proton relaxation giving improved MRI contrast and allowing smaller MNPs core use without compromising sensitivity. However, water-soluble Co NPs is very difficult to obtain and stabilizer, besides their high toxicity intrinsic to the metal NPs. As observed with $\mathrm{Co}, \mathrm{Fe}$ and FePt NPs present advantage 
compared with the oxide for enhanced MRI contrast, but their potential uses require further improvement in biostabilization and functionalization because their toxicity. In addition, the negative contrast effect and magnetic susceptibility artifacts of iron oxide NPs are significant drawbacks. The resulting dark signal can mislead the clinical diagnosis in $\mathrm{T}_{2}$-weighted MRI because the signal is often confused with the signals from bleeding, calcification, or metal deposits, and the susceptibility artifacts distort the background image. For the extensive applications of MRI to diagnostic radiology and therapeutic medicine and to overcome the above-mentioned drawbacks of $\mathrm{Gd}^{3+}$ - and $\mathrm{Mn}^{2+}$-based $\mathrm{T}_{1}$ contrast agents and MNP-based $\mathrm{T}_{2}$ contrast agents, there has been great demand for a new class of contrast agent that satisfies the following characteristics: 1) positive $\left(T_{1}\right)$ contrast ability, 2) intracellular uptake and accumulation for imaging cellular distribution and functions, 3) nanoparticulate form for easy surface modification and efficient labeling with targeting agents for applications in molecular and cellular imaging, and 4) favorable pharmacokinetics and dynamics for easy delivery, efficient distribution to biomarkers, and safe clearance from patients with minimal side effects. Recently, the development of a long-awaited $\mathrm{T}_{1}$ MRI contrast agent that satisfies all of these desirable characteristics was proposed by using MnO NPs (Na et al., 2007).

\subsection{Drug delivery and gene delivery (magnetofection)}

The surface of magnetite NPs have been functionalized with drugs, proteins, and genetic materials to achieve localized delivery of therapeutic agents. The need for localized delivery of bioactive agents stems in the systemic toxicity often associated with non-targeted administration of these agents. Potential elimination of systemic side-effects could potentially be achieved through efficient targeting of NPs carrying high payload of active agents. Although still the object of much debate the ability to magnetically target in vivo drug-loaded MNPs has attracted considerable attention (Dobson, 2006a). Whether an external magnetic field can be used to capture MNPs injected intravenously depends on the strength of the applied magnetic field, as well as on the magnetic properties and volume of the NPs. Alternatively, targeting moieties on the surface of the NPs functionalized with bioactive agents have been used to target or internalize specific tissue or tumor in vivo. Ideally, they could bear on their surface or in their bulk a pharmaceutical drug that could be driven to the target organ and released there. Physical constraints placed upon magnetic targeting, such as the rapid diminishing of field strength with target depth in the body and the difficulties of bypassing intervening vasculature and tissue structures (Dobson, 2006a; Dobson, 2006b), have hampered the clinical realization of this technology. Much of the recent work in this area has focused on the development of high-moment MNP carriers with novel, multifunctional coatings and novel techniques for enhancing the body own targeting systems (Pankhurst et al., 2009). The development of novel MNP carrier formulations continues apace. In general, advances are focusing on novel, multifunctional coatings, and the use of high-moment materials for the particle cores and the development of thermoresponsive hydrogels and particles (Ankareddi \& Brazel, 2007). Although there have been numerous small animal studies reported since our last review, due to the technical barriers mentioned above, the goal of clinical applications remains largely unfulfilled.

Magnetofection (MF) is a method in which MNPs associated with vector DNA are transfected into cells by the influence of an external magnetic field. A high-field, highgradient magnet is generally placed underneath a cell culture dish or multi-well plate. The particle-gene complex is introduced into the cell growth medium and the magnetic field 
rapidly pulls the particles into contact with the cells growing on the bottom of the dish. This has been shown to promote endocytosis of the particles, resulting in rapid and efficient transfection (Pankhurst et al., 2003). By using whether viral or nonviral vectors, MF has been shown to enhance the efficiency of the vectors up to several thousand times.

\subsection{Hyperthermia}

The idea of hyperthermia has been recognized as a useful therapeutic modality for treating malignant tumors, the idea being that it may be possible to kill cancer, not with drugs, but with targeted nanoscale heaters that would essentially cook malignant cells to death from the inside out. Magnetic materials with Curie temperatures between 42 and $60{ }^{\circ} \mathrm{C}$ are the best candidates for effective treatment, since they act as in vivo temperature control switches, preventing overheating. It is known that tumor cells are more sensitive to temperature increases than healthy cells, therefore intracellular hyperthermia methods have been suggested and developed using MNPs, whereby the particles are concentrated at the tumor site and remotely heated using an applied magnetic field to required hyperthermic temperatures $\left(42-45^{\circ} \mathrm{C}\right)$ by hysteresis loss (multidomain particles) or energy dissipation (superparamagnetic NPs) (Berry, 2009). Magnetic field is not absorbed by the living tissues and can be applied to deep region in the living body. The amount of heat generated depends on the nature of magnetic material and of magnetic field parameters. Magnetic particles embedded around a tumor site and placed within an oscillating magnetic field will heat up to a temperature dependent on the magnetic properties of the material, the strength of the magnetic field, and the frequency of oscillation and the cooling capacity of the blood flow in the tumor site. Cancer cells are destroyed at temperature higher than $43{ }^{\circ} \mathrm{C}$, whereas the normal cells can survive at higher temperatures (Gupta \& Gupta, 2005). In a general way, when MNPs are injected into an organ with a tumor, they tend to accumulate in the tumor due to the unorganized vasculature, thus effectively heating the tumor as opposed to the surrounding healthy tissue. Direct injection into solid tumors, followed by exposure to an alternating magnetic field, has been shown to be capable of inducing tumor regression. Studies have highlighted the potential of MNPs in human cancer models, such as breast cancer, whereby 10-30 nm iron oxide particles were heated effectively. Choosing highpower magnetic particles combined with appropriate external magnetic field, very small amounts of magnetic fine particles in the order of tenth of milligram may easily be used to raise the temperature of biological tissue locally up to cell necrosis. However, the major technical difficulty associated with heat-based cancer therapy is to heat only the tumor tissues without damaging the healthy ones. Considerable interest has therefore been drawn to MNP to achieve intracellular hyperthermia procedures, for instance by targeting MNPs conjugated with a monoclonal antibody such as anti-HER2. In addition, if it is the aim to generate enough of a temperature rise throughout the target tissue volume for the induced hyperthermia to be therapeutic in its own right, then the method used to get the NPs into the target becomes critical (Wust et al., 2006). MagForce have pursued the concept of interstitial heating via multiple-site direct injection of their NPs and have developed sophisticated measures to ensure that the specific absorption rate (SAR) throughout the entire target volume will be enough to result in a therapeutic thermal dose, expressed as cumulative equivalent minutes at 43 C for $90 \%$ of the tumor volume (Pankhurst et al., 2009). This is an extremely demanding requirement since it only requires a very small part of the target volume to remain cool for the entire treatment to be compromised. The two 
most obvious reasons why a small section of a tumor may not be heated are either because of a locally increased level of blood flow, say because of a nearby blood vessel, or an inadequate concentration of implanted MNPs.

A study highlights the difficulty in obtaining a uniformly effective thermal dose throughout the tumor volume. Animal model was used to examine the effect on tumor growth of NPmediated hyperthermia by comparing two methods of NP administration. In one group, small deposits of a viscous emulsion of MNPs were injected directly into the centre of the tumors (group 1), while in the second group microspheres (ca $30 \mu \mathrm{m}$ in diameter) containing the same type of MNPs were administered via the arterial blood supply to the tumors (group 2). In both cases the thermal response, as measured by discrete temperature probes located in and around the tumor, appeared to be adequate although the group 1 heated much more rapidly than the group 2 . The somewhat unexpected result, however, was that the therapeutic outcomes were very different and revealed a distinct advantage of the second approach, despite an apparently inferior thermal response initially. This result could be explained by the differences in the distribution of the magnetic particles throughout the tumor that are not reflected in the measured thermal response (Moroz et al., 2002).

\subsection{Tissue repair - tissue engineering (TE) and regenerative medicine (RM)}

Tissue repair using MNPs is accomplished either through welding, apposing two tissue surfaces then heating the tissues sufficiently to join them, or through soldering, where protein or synthetic polymer-coated NPs are placed between two tissue surfaces to enhance joining of the tissues. Temperatures greater than $50^{\circ} \mathrm{C}$ are known to induce tissue union. This is believed to be induced by the denaturation of proteins and the subsequent entanglement of adjacent protein chains (Gupta \& Gupta, 2005). NPs that strongly absorb light corresponding to the output of a laser are also useful for tissue-repairing procedures. Specifically, gold- or silica-coated MNPs have been designed to strongly absorb light. The NPs are coated onto the surfaces of two pieces of tissue at the site where joining was desired. This technique affords methods to minimize tissue damage by using the least harmful wavelengths of light and/or lower powered light sources. Stem cells are the body master cells and have a unique ability to renew them and give rise to other specialized cell types. These cells, therefore, have the potential to be used for transplantation purposes, for example, to replace degenerated cells or repairing of a damaged tissue, providing signals so that the stem cells can yield the appropriate cell types for the development of a tissue. An obstacle to developing such therapy is a lack of targeting strategies on both neural stem cells and on the signals that determine their behavior and fate for tissue development. The superparamagnetic NPs could be coupled to the cells and used to target these cells at the desired site in the body. In addition, various proteins, growth factors, etc., could be bound to these NPs that might be delivered at the damaged tissue, where it would play a role in tissue development (Gupta \& Gupta, 2005). In this context, over the past decade another novel application of MNPs has emerged: nanomagnetic actuation for TE and RM. Magnetic actuation can also be used to influence the growth and differentiation characteristics of stem cells. For many TE/RM applications, mechanical cues provide vitally important stimuli to the cells that promote the production of functional tissue matrix, especially bone, cartilage, muscle and connective tissue. However, applying the correct stress profiles to cells growing in a 3D scaffold within a bioreactor or within a patient's body has proven difficult. To overcome this problem, nanomagnetic actuation has been developed to apply targeted, controlled stress to cells growing in bioreactors and in vivo (Pankhurst et al., 2009). Although 
the use of MNPs for TE/RM and stem cell research and therapy is at an early stage, the potential for this technology to make a major contribution to this field is great.

\subsection{Cellular labeling and cell separation}

Cell labeling with MNPs is an increasingly common method for in vivo cell separation (Olsvik et al., 1994) as the labeled cells can also be detected by MRI. Most current labeling techniques utilize either of two approaches: (a) attaching MNPs to the cell surface or (b) internalizing biocompatible magnetic particles by fluid phase endocytosis, receptormediated endocytosis or phagocytosis (Gupta \& Gupta, 2005). One strategy for efficient and specific cell labelling of MNPs is to modify their surface with a ligand efficient to taken up by target cells. Targeting agents (e.g. transferrin, lactoferrin, albumin, insulin, growth factors, etc.) have been shown preference for target cell surface, because the receptors for these ligands are frequently overexpressed on the mammalian cells surface (Qian et al., 2002). These receptors are not only cellular markers, but also have been shown efficiency in the internalize molecules coupled to them. Furthermore, many of these ligands are stable, and generally poorly immunogenic. In the absence of any system to inhibit endocytosis, most NPs are endocytosed by cells and eventually sequestered in digestive vacuoles in the cell. Once the particles are endocytosed, they are probably removed from contact with specific cell surface receptors and become effectively ineffective. As a result of these events, the cells are at high risk of apoptosis from overload with particles. If the particles can be prevented from leaving the cell surface, they will remain in contact with their specific receptors and would be expected to leave the cell in a state of prolonged stimulation while protecting the cells from side effects due to endocytosis (Gupta \& Gupta, 2005).

\section{Challengers and trends}

Although significant advances were obtained, the challengers faced by using MNPs in vivo still remains such as: need to extend the particles blood circulation time, the difficult to targeting specific tissue, and, more recently, due to increasing the complexity of the multifunctions by derivatized-layered coating the MNP surface generally using no-magnetic materials, there is a need to improve the magnetic core emanation in order to support these multifunctional capping. The need to extend NPs blood circulation time to allow for their accumulation in target tissues has long been recognized as one of the primary challenges in the development of MNPs (Berry, 2009; Sun et al., 2008). The ability to evade uptake by the RES is critical to achieving a long blood half-life. Like other colloidal carriers, the physicochemical properties of these MNP platforms, such as size, morphology, charge, and surface chemistry, dictate their fate in vivo, since determine their pharmacokinetics, toxicity, and biodistribution. The overall size of MNPs must be sufficiently small to evade rapid splenic filtration but large enough to avoid renal clearance. NPs larger than $200 \mathrm{~nm}$ are sequestered by phagocytotic cells of the spleen, while particles smaller than $5.5 \mathrm{~nm}$ are rapidly removed through renal clearance (Berry, 2009). In addition, particles smaller than 40 $\mathrm{nm}$ present both biodistribution and half-life determined by the coating materials rather than the mean hydrated size (Briley-Saebo et al., 2004). Particles that escape filtration are then subject to opsonization resulting in recognition and clearance by Kupffer cells and other tissue macrophages. Coatings including hydrophilic polymers, such as PEG, have been utilized to create a non-fouling coating on the particle surface. In addition to the biofouling nature of MNPs, surface charge plays a critical role in blood half-lives of colloids 
and polymers. Positively charged polymers and particles tend to non-specifically stick to cells. This non-specific adsorption can have a significant impact on blood half-life. Strong negative charges on the particle surface are also detrimental in that they result in increased liver uptake. Therefore, it is generally agreed that NPs with a neutral surface experience extended blood circulation times. The development of long-circulating NPs has allowed for many MNP platforms to exploit structural abnormalities in the vasculature of particular pathologies, such as tumors, inflammatory, and infectious sites. This phenomenon, known as the enhance permeability and retention (EPR) effect, is based on the mechanism that these tissues possess "leaky" vasculature which allows macromolecules and NPs to extravasate and accumulate more readily. In the case of tumors, poorly organized vascular beds also result in impaired lymphatic drainage from these tissues. This nonspecific accumulation, or passive targeting, has been demonstrated with NPs ranging from 10 to $500 \mathrm{~nm}$ in diameter. Passive targeting can also occur through the inherent clearance by the RES. Comprised of bone marrow progenitors, blood monocytes, and tissue macrophages, the uptake of MNPs by these phagocytic cells provides a means of delivering contrast agents and drug carriers to related organs. One promising approach toward increasing the local accumulation of MNPs in diseased tissue, known as active targeting or specific targeting, is by the conjugation of targeting molecules that possess high affinity toward unique molecular signatures found on malignant cells. Often augmented by the EPR effect, these receptor-ligand or antigenantibody interactions provide an effective strategy to improve the residence time in malignant tissues, such as tumors. Targeting ligands, such as proteins, peptides, aptamers, and small molecules, have been investigated to increase the site specific accumulation of MNPs. In some cases, specific binding can also facilitate internalization of the NP by receptor-mediated endocytosis. Another area of extensive investigation has been the targeting of MNPs to receptors overexpressed on tumor neovasculature. The formation of new blood vessels, or angiogenesis, is an essential component of tumor growth and has been shown to be highly specific for neoplasia (Sun et al., 2008). The use of short peptides and small molecules as targeting agents also offers the advantage of increased binding affinity through multivalent attachment (Weissleder et al., 2005). This targeting phenomenon has been examined with folic acid, a vitamin whose receptor is overexpressed on the surface of many human tumor cells, including ovarian, lung, breast, endometrial, renal, and colon cancers (Ross et al., 1994). Another advantage of utilizing small molecules as targeting agents is that they are generally more robust than proteins or peptides thereby reducing possibility of loss of functionality through the synthesis of such MNPs. An essential step in the use of MNPs for drug delivery is the internalization of the MNP and/or its therapeutic payload, as well as the subsequent release of these therapeutic agents to cell cytoplasm for desired actions to take place. Several mechanisms have been proposed to describe the uptake of NPs into cells, including receptor-mediated endocytosis and internalization by caveolae structures (Berry \& Curtis, 2003). NP size and surface properties play a critical role in moving across the plasma membrane. NPs smaller than $50 \mathrm{~nm}$ or those coated with lipophilic polymers, such as PEG, have been shown to efficiently diffuse through cell membranes (Zhang et al., 2002). Although general guidelines, such as those discussed in regard to the physicochemical properties of MNPs, may provide some insight on their behavior in the body, no universal set of criteria has been elucidated to predict this critical aspect of nanomedicine. Mechanisms of clearance can vary significantly depending on the wide range of structures that are employed in the development of MNPs. One can make the obvious distinction that the metabolism, clearance, and toxicity profiles associated with a 
gold-coated FePt core-shell NP will be drastically different from that of an iron oxide filled liposome and these structures therefore necessitate their individual evaluation. Recently, increased emphasis has been placed on standardizing preclinical characterization of biomedical NPs to better elucidate structure-activity relationships (SARs) (Sun et al., 2008).

Recently, a new challenger involving MNPs or MFMNPs seems to be related with the core emanation. Several coating and molecular/compounds used to change de MNP surface from naked to multifunctional biocompatible and targeting leads also to dramatically decrease in the magnetic core emanation. In this context, either, new magnetic materials or combined magnetic materials in an enhanced new composite must be used in order to preserve the magnetic signal response of the external field (Varanda et al., 2008).

\section{Conclusion}

Progress and uses of MNPs in biomedicine have been highlighted, in both the traditional targeting and imaging, as well as the more novel cell manipulation techniques, it is believed that the future of MNP development must be directed towards further improving on the biocompatibility, specific targeting and image resolution available, extent the blood circulation time, and improvement of the magnetic core emanation in order to support the additional coating for multifunctionality. In addition, the potential of MNPs to have a multifunctional role in diagnosis, monitoring and treatment, is an exciting prospect.

\section{Acknowledgments}

Authors thank the Brazilian agencies FAPESP and $C N P q$ by the financial support.

\section{References}

Ankareddi, I. \& Brazel, C.S.(2007). Synthesis and characterization of grafted thermosensitive hydrogels for heating activated controlled release. Int. J. Pharm., Vol. 336, No 2, 241247, ISSN: 0378-5173.

Batlle, X. \& Labarta, A. (2002). Finite-size effects in fine particles: magnetic and transport properties. J. Phys. D-Appl. Phys., Vol. 35, No 6, R15-R42, ISSN: 0022-3727.

Benitez, M. J.; Petracic, O.; Salabas, E. L.; Radu, F.; Tuysuz, H.; Schuth, F. \& Zabel, H. (2008). Evidence for core-shell magnetic behavior in antiferromagnetic $\mathrm{Co}_{3} \mathrm{O}_{4}$ nanowires. Phys. Rev. Lett., Vol. 101, No 9, ISSN: 0031-9007.

Berry, C. C. (2009). Progress in functionalization of magnetic nanoparticles for applications in biomedicine. J. Phys. D-Appl. Phys., Vol. 42, No 22, ISSN: 0022-3727.

Berry, C. C. \& Curtis, A. S. G. (2003). Functionalisation of magnetic nanoparticles for applications in biomedicine. J. Phys. D-Appl. Phys., Vol. 36, No 13, R198-R206, ISSN: 0022-3727.

Bin Na, H.; Lee, I. S.; Seo, H.; Il Park, Y.; Lee, J. H.; Kim, S. W. \& Hyeon, T. (2007). Versatile PEG-derivatized phosphine oxide ligands for water-dispersible metal oxide nanocrystals. Chem. Commun., No 48, 5167-5169, ISSN: 1359-7345.

Briley-Saebo, K.; Bjornerud, A.; Grant, D.; Ahlstrom, H.; Berg, T. \& Kindberg, G. M. (2004). Hepatic cellular distribution and degradation of iron oxide nanoparticles following single intravenous injection in rats: implications for magnetic resonance imaging. Cell Tissue Res., Vol. 316, No 3, 315-323, ISSN: 0302-766X. 
Brus, C.; Petersen, H.; Aigner, A.; Czubayko, F. \& Kissel, T. (2004). Physicochemical and biological characterization of polyethylenimine-graft-poly(ethylene glycol) block copolymers as a delivery system for oligonucleotides and ribozymes. Bioconjugate Chem., Vol. 15, No 4, 677-684, ISSN: 1043-1802.

Burugapalli, K.; Koul, V. \& Dinda, A. K. (2004). Effect of composition of interpenetrating polymer network hydrogels based on poly(acrylic acid) and gelatin on tissue response: A quantitative in vivo study. J. Biomed. Mater. Res. Part A, Vol. 68A, No 2, 210-218, ISSN: 0021-9304.

Cornell, R. M. \& Schwertmann, U. (2003). The iron oxide. Structure, properties, reaction, occurrence and uses, Wiley-VCH, ISBN: 3-527-30274-3, Weiheim, Germany.

Corr, S. A.; Rakovich, Y. P. \& Gun'ko, Y. K. (2008). Multifunctional magnetic-fluorescent nanocomposites for biomedical applications. Nanoscale Res. Lett., Vol. 3, No 3, 87104, ISSN: 1931-7573.

Cushing, B. L.; Kolesnichenko, V. L. \& O'Connor, C. J. (2004). Recent advances in the liquidphase syntheses of inorganic nanoparticles. Chem. Rev., Vol. 104, No 9, 3893-3946, ISSN: 0009-2665.

de Dios, A. S. \& Díaz-Garcia, M. E. (2010). Multifunctional nanoparticles: Analytical prospects. Anal. Chim. Acta, Vol. 666, No 1-2, 1-22, ISSN: 0003-2670.

Denizot, B.; Tanguy, G.; Hindre, F.; Rump, E.; Le Jeune, J. J. \& Jallet, P. (1999). Phosphorylcholine coating of iron oxide nanoparticles. J. Colloid Interface Sci., Vol. 209, No 1, 66-71, ISSN: 0021-9797.

Dobson, J. (2006a). Magnetic nanoparticles for drug delivery. Drug Dev. Res., Vol. 67, No 1, 55-60, ISSN: 0272-4391.

Dobson, J. (2006b). Magnetic micro- and nano-particle-based targeting for drug and gene delivery. Nanomedicine, Vol. 1, No 1, 31-37, ISSN: 1743-5889.

Gupta, A. K. \& Curtis, A. S. G. (2004). Surface modified superparamagnetic nanoparticles for drug delivery: Interaction studies with human fibroblasts in culture. J. Mater. Sci.Mater. Med., Vol. 15, No 4, 493-496, ISSN: 0957-4530.

Gupta, A. K. \& Gupta, M. (2005). Synthesis and surface engineering of iron oxide nanoparticles for biomedical applications. Biomaterials, Vol. 26, No 18, 3995-4021, ISSN: 0142-9612.

Gupta, A. K.; Naregalkar, R. R.; Vaidya, V. D. \& Gupta, M. (2007). Recent advances on surface engineering of magnetic iron oxide nanoparticles and their biomedical applications. Nanomedicine, Vol. 2, No 1, 23-39, ISSN: 1743-5889.

Gupta, A. K. \& Wells, S. (2004). Surface-modified superparamagnetic nanoparticles for drug delivery: Preparation, characterization, and cytotoxicity studies. IEEE Trans. Nanobiosci., Vol. 3, No 1, 66-73, ISSN: 1536-1241.

Hu, F. Q.; Wei, L.; Zhou, Z.; Ran, Y. L.; Li, Z. \& Gao, M. Y. (2006). Preparation of biocompatible magnetite nanocrystals for in vivo magnetic resonance detection of cancer. Adv. Mater., Vol. 18, No 19, 2553-+, ISSN: 0935-9648.

Hunter, R. J. (2001). Foundations of colloid science, Oxford University Press, ISBN: 0198505027, Oxford, UK.

Hyeon, T. (2003a). Synthesis of monodisperse and highly-crystalline nanoparticles of metal, alloys, metal oxides, and multi-metallic oxides without a size-selection process. Korea, Patent $\mathrm{N}^{\circ}$ WO 03/031323. 
Hyeon, T. (2003b). Chemical synthesis of magnetic nanoparticles. Chem. Commun., Vol. 8, 927-934, ISSN: 1359-7345.

Hyeon, T.; Lee, S. S.; Park, J.; Chung, Y. \& Na, H. B. (2001). Synthesis of highly crystalline and monodisperse maghemite nanocrystallites without a size-selection process. J. Am. Chem. Soc., Vol. 123, 12798-12801, ISSN: 0002-7863.

Kohler, N.; Fryxell, G. E. \& Zhang, M. Q. (2004). A bifunctional poly(ethylene glycol) silane immobilized on metallic oxide-based nanoparticles for conjugation with cell targeting agents. J. Am. Chem. Soc., Vol. 126, No 23, 7206-7211, ISSN: 0002-7863.

LaMer, V. K. \& Dinegar, R. H. (1950). Theory, production and mechanism of formation of monodispersed hydrosols. J. Am. Chem. Soc., Vol. 72, No 11, 4847-4855, ISSN: 00027863.

Li, Z.; Sun, Q. \& Gao, M. Y. (2005). Preparation of water-soluble magnetite nanocrystals from hydrated ferric salts in 2-pyrrolidone: Mechanism leading to $\mathrm{Fe}_{3} \mathrm{O}_{4}$. Angew. Chem. Int. Edit., Vol. 44, No 1, 123-126, ISSN: 1433-7851.

Lu, A. H.; Salabas, E. L. \& Schuth, F. (2007). Magnetic nanoparticles: Synthesis, protection, functionalization, and application. Angew. Chem.-Int. Edit., Vol. 46, No 8, 1222-1244, ISSN: 1433-7851.

Lu, Y.; Yin, Y. D.; Mayers, B. T. \& Xia, Y. N. (2002). Modifying the surface properties of superparamagnetic iron oxide nanoparticles through a sol-gel approach. Nano Lett., Vol. 2, No 3, 183-186, ISSN: 1530-6984.

Luo, F.; Su, H. L.; Song, W.; Wang, Z. M.; Yan, Z. G. \& Yan, C. H. (2004). Magnetic and magnetotransport properties of $\mathrm{Fe}_{2} \mathrm{P}$ nanocrystallites via a solvothermal route. J. Mater. Chem., Vol. 14, No 1, 111-115, ISSN: 0959-9428.

Majewski, P. \& Thierry, B. (2007). Functionalized magnetite nanoparticles - Synthesis, properties, and bio-applications. Crit. Rev. Solid State Mat. Sci., Vol. 32, No 3-4, 203215, ISSN: 1040-8436.

Malheiro, A. R.; Varanda, L. C.; Perez, J. \& Villullas, H. M. (2007). The aerosol OT plus nbutanol plus n-heptane plus water system: Phase behavior, structure characterization, and application to $\mathrm{Pt}_{70} \mathrm{Fe}_{30}$ nanoparticle synthesis. Langmuir, Vol. 23, No 22, 11015-11020, ISSN: 0743-7463.

Massia, S. P.; Stark, J. \& Letbetter, D. S. (2000). Surface-immobilized dextran limits cell adhesion and spreading. Biomaterials, Vol. 21, No 22, 2253-2261, ISSN: 0142-9612.

Mikhaylova, M.; Kim, D. K.; Bobrysheva, N.; Osmolowsky, M.; Semenov, V.; Tsakalakos, T. \& Muhammed, M. (2004). Superparamagnetism of magnetite nanoparticles: Dependence on surface modification. Langmuir, Vol. 20, No 6, 2472-2477, ISSN: 0743-7463.

Mokari, T.; Rothenberg, E.; Popov, I.; Costi, R. \& Banin, U. (2004). Selective growth of metal tips onto semiconductor quantum rods and tetrapods. Science, Vol. 304, No 5678, 1787-1790, ISSN: 0036-8075.

Mornet, S.; Vasseur, S.; Grasset, F.; Veverka, P.; Goglio, G.; Demourgues, A.; Portier, J.; Pollert, E. \& Duguet, E. (2006). Magnetic nanoparticle design for medical applications. Prog. Solid State Chem., Vol. 34, No 2-4, 237-247, ISSN: 0079-6786.

Moroz, P.; Jones, S. K. \& Gray, B. N. (2002). Tumor response to arterial embolization hyperthermia and direct injection hyperthermia in a rabbit liver tumor model. $J$. Surg. Oncol., Vol. 80, No 3, 149-156, ISSN: 0022-4790. 
Na, H. B.; Lee, J. H.; An, K. J.; Park, Y. I.; Park, M.; Lee, I. S.; Nam, D. H.; Kim, S. T.; Kim, S. H.; Kim, S. W.; Lim, K. H.; Kim, K. S.; Kim, S. O. \& Hyeon, T. (2007). Development of a T-1 contrast agent for magnetic resonance imaging using $\mathrm{MnO}$ nanoparticles. Angew. Chem. Int. Edit., Vol. 46, No 28, 5397-5401, ISSN: 1433-7851.

Nandivada, H.; Jiang, X. W. \& Lahann, J. (2007). Click chemistry: Versatility and control in the hands of materials scientists. Adv. Mater., Vol. 19, No 17, 2197-2208, ISSN: 09359648.

O'Brien, S.; Brus, L. \& Murray, C. B. (2001). Synthesis of monodisperse nanoparticles of barium titanate: Toward a generalized strategy of oxide nanoparticle synthesis. J. Am. Chem. Soc., Vol. 123, No 48, 12085-12086, ISSN: 0002-7863.

O'Connor, C. J.; Seip, C. T.; Carpenter, E. E.; Li, S. C. \& John, V. T. (1999). Synthesis and reactivity of nanophase ferrites in reverse micellar solutions. Nanostruct. Mater., Vol. 12, No 1-4, 65-70, ISSN: 0965-9773.

Olsvik, O.; Popovic, T.; Skjerve, E.; Cudjoe, K. S.; Hornes, E.; Ugelstad, J. \& Uhlen, M. (1994). Magnetic Separation Techniques in Diagnostic Microbiology. Clin. Microbiol. Rev., Vol. 7, No 1, 43-54, ISSN: 0893-8512.

Pankhurst, Q. A.; Connolly, J.; Jones, S. K. \& Dobson, J. (2003). Applications of magnetic nanoparticles in biomedicine. J. Phys. D-Appl. Phys., Vol. 36, No 13, R167-R181, ISSN: 0022-3727.

Pankhurst, Q. A.; Thanh, N. K. T.; Jones, S. K. \& Dobson, J. (2009). Progress in applications of magnetic nanoparticles in biomedicine. J. Phys. D-Appl. Phys., Vol. 42, No 22, ISSN: 0022-3727.

Park, J.; An, K. J.; Hwang, Y. S.; Park, J. G.; Noh, H. J.; Kim, J. Y.; Park, J. H.; Hwang, N. M. \& Hyeon, T. (2004). Ultra-large-scale syntheses of monodisperse nanocrystals. Nat. Mater., Vol. 3, No 12, 891-895, ISSN: 1476-1122.

Portet, D.; Denizot, B.; Rump, E.; Lejeune, J. J. \& Jallet, P. (2001). Nonpolymeric coatings of iron oxide colloids for biological use as magnetic resonance imaging contrast agents. J. Colloid Interface Sci., Vol. 238, No 1, 37-42, ISSN: 0021-9797.

Pratsinis, S. E. \& Vemury, S. (1996). Particle formation in gases: A review. Powder Technol., Vol. 88, No 3, 267-273, ISSN: 0032-5910.

Puntes, V. F.; Krishnan, K. M. \& Alivisatos, A. P. (2001). Colloidal nanocrytal shape and size control: the case of cobalt. Science, Vol. 291, 2115-2117,

Qian, Z. M.; Li, H. Y.; Sun, H. Z. \& Ho, K. (2002). Targeted drug delivery via the transferrin receptor-mediated endocytosis pathway. Pharmacol. Rev., Vol. 54, No 4, 561-587, ISSN: 0031-6997.

Rishton, S. A.; Lu, Y.; Altman, R. A.; Marley, A. C.; Bian, X. P.; Jahnes, C.; Viswanathan, R.; Xiao, G.; Gallagher, W. J. \& Parkin, S. S. P. (1997). Magnetic tunnel junctions fabricated at tenth-micron dimensions by electron beam lithography. Microelectron. Eng., Vol. 35, No 1-4, 249-252, ISSN: 0167-9317.

Roca, A. G.; Costo, R.; Rebolledo, A. F.; Veintemillas-Verdaguer, S.; Tartaj, P.; GonzalezCarreno, T.; Morales, M. P. \& Serna, C. J. (2009). Progress in the preparation of magnetic nanoparticles for applications in biomedicine. J. Phys. D-Appl. Phys., Vol. 42, No 22, ISSN: 0022-3727.

Ross, J. F.; Chaudhuri, P. K. \& Ratnam, M. (1994). Differential Regulation of Folate Receptor Isoforms in Normal and Malignant-Tissues In-Vivo and in Established Cell-Lines - 
Physiological and Clinical Implications. Cancer, Vol. 73, No 9, 2432-2443, ISSN: 0008-543X.

Sahoo, Y.; Pizem, H.; Fried, T.; Golodnitsky, D.; Burstein, L.; Sukenik, C. N. \& Markovich, G. (2001). Alkyl phosphonate/phosphate coating on magnetite nanoparticles: A comparison with fatty acids. Langmuir, Vol. 17, No 25, 7907-7911, ISSN: 0743-7463.

Salgueirino-Maceira, V. \& Correa-Duarte, M. A. (2007). Increasing the complexity of magnetic core/shell structured nanocomposites for biological applications. Adv. Mater., Vol. 19, No 23, 4131-4144, ISSN: 0935-9648.

Santos, F. J.; Varanda, L. C.; Ferracin, L. C. \& Jafelicci, M. (2008). Synthesis and electrochemical behavior of single-crystal magnetite nanoparticles. J. Phys. Chem. C, Vol. 112, No 14, 5301-5306, ISSN: 1932-7447.

Sanvicens, N. \& Marco, M. P. (2008). Multifunctional nanoparticles - properties and prospects for their use in human medicine. Trends Biotechnol., Vol. 26, No 8, 425-433, ISSN: 0167-7799.

Selvan, S. T.; Tan, T. T. Y.; Yi, D. K. \& Jana, N. R. (2010). Functional and Multifunctional Nanoparticles for Bioimaging and Biosensing. Langmuir, Vol. 26, No 14, 1163111641, ISSN: 0743-7463.

Shi, W. L.; Sahoo, Y.; Zeng, H.; Ding, Y.; Swihart, M. T. \& Prasad, P. N. (2006). Anisotropic growth of PbSe nanocrystals on $\mathrm{Au}-\mathrm{Fe} 3 \mathrm{O} 4$ hybrid nanoparticles. Adv. Mater., Vol. 18, No 14, 1889-+, ISSN: 0935-9648.

Sorensen, C. M. (2001). Magnetism, In: Nanoscale Materials in Chemistry, Klabunde, K. J. (Ed.), 169-221, Wiley-Interscience Publications, ISBN: 9780471383956, New York.

Stoner, E. C. \& Wohlfarth, E. P. (1948). A Mechanism of Magnetic Hysteresis in Heterogeneous Alloys. Phil. Trans. R. Soc. A, Vol. 240, No 826, 599-642, ISSN: 00804614 .

Sun, C.; Lee, J. S. H. \& Zhang, M. Q. (2008). Magnetic nanoparticles in MR imaging and drug delivery. Adv. Drug Deliv. Rev., Vol. 60, No 11, 1252-1265, ISSN: 0169-409X.

Sun, S.; Murray, C. B.; Weller, D.; Folks, L. \& Moser, A. (2000). Monodispersed FePt nanoparticles and ferromagnetic FePt nanocrystal superlattices. Science, Vol. 287, 1989-1992, ISSN: 0036-8075.

Sun, S. \& Zeng, H. (2002). Size-controlled synthesis of magnetite nanoparticles. J. Am. Chem. Soc., Vol. 124, 8204-8205, ISSN: 0002-7863.

Sutton, D.; Nasongkla, N.; Blanco, E. \& Gao, J. M. (2007). Functionalized micellar systems for cancer targeted drug delivery. Pharm. Res., Vol. 24, No 6, 1029-1046, ISSN: 07248741.

Tada, D. B.; Vono, L. L. R.; Duarte, E. L.; Itri, R.; Kiyohara, P. K.; Baptista, M. S. \& Rossi, L. M. (2007). Methylene blue-containing silica-coated magnetic particles: A potential magnetic carrier for photodynamic therapy. Langmuir, Vol. 23, No 15, 8194-8199, ISSN: 0743-7463.

Torchilin, V. P. (2005). Recent advances with liposomes as pharmaceutical carriers. Nat. Rev. Drug Discov., Vol. 4, No 2, 145-160, ISSN: 1474-1776.

Varanda, L. C.; Goya, G. F.; Morales, M. P.; Marques, R. F. C.; Godoi, R. H. M.; Jafelicci, M. \& Serna, C. J. (2002a). Magnetic properties of acicular ultrafine iron particles. IEEE Trans. Magn., Vol. 38, No 5, 1907-1909, ISSN: 0018-9464.

Varanda, L. C.; Imaizumi, M.; Santos, F. J. \& Jafelicci, M. (2008). Iron Oxide Versus $\mathrm{Fe}_{55} \mathrm{Pt}_{45} / \mathrm{Fe}_{3} \mathrm{O}_{4}$ : Improved Magnetic Properties of Core/Shell Nanoparticles for 
Biomedical Applications. IEEE Trans. Magn., Vol. 44, No 11, 4448-4451, ISSN: 00189464.

Varanda, L. C. \& Jafelicci, M. (2006). Self-assembled FePt nanocrystals with large coercivity: Reduction of the fcc-to-L1 $(0)$ ordering temperature. J. Am. Chem. Soc., Vol. 128, No 34, 11062-11066, ISSN: 0002-7863.

Varanda, L. C.; Jafelicci, M. \& Goya, G. F. (2001). Magnetic properties of spindle-type iron fine particles obtained from hematite. J. Magn. Magn. Mater., Vol. 226, 1933-1935, ISSN: 0304-8853.

Varanda, L. C.; Jafelicci, M. \& Imaizumi, M. (2007). Temperature dependence and magnetocrystalline anisotropy studies of self-assembled $\mathrm{L1}_{(0)}-\mathrm{Fe}_{55} \mathrm{Pt}_{45}$ ferromagnetic nanocrystals. J. Appl. Phys., Vol. 101, No 12, ISSN: 0021-8979.

Varanda, L. C.; Jafelicci, M.; Tartaj, P.; O' Grady, K.; Gonzalez-Carreno, T.; Morales, M. P.; Munoz, T. \& Serna, C. J. (2002b). Structural and magnetic transformation of monodispersed iron oxide particles in a reducing atmosphere. J. Appl. Phys., Vol. 92, No 4, 2079-2085, ISSN: 0021-8979.

Vonarbourg, A.; Passirani, C.; Saulnier, P. \& Benoit, J. P. (2006). Parameters influencing the stealthiness of colloidal drug delivery systems. Biomaterials, Vol. 27, No 24, 43564373, ISSN: 0142-9612.

Weinmann, H. J.; Ebert, W.; Misselwitz, B. \& Schmitt-Willich, H. (2003). Tissue-specific MR contrast agents. Eur. J. Radiol., Vol. 46, No 1, 33-44, ISSN: 0720-048X.

Weissleder, R.; Kelly, K.; Sun, E. Y.; Shtatland, T. \& Josephson, L. (2005). Cell-specific targeting of nanoparticles by multivalent attachment of small molecules. Nat. Biotechnol., Vol. 23, No 11, 1418-1423, ISSN: 1087-0156.

Willis, A. L.; Turro, N. J. \& O'Brien, S. (2005). Spectroscopic characterization of the surface of iron oxide nanocrystals. Chem. Mat., Vol. 17, No 24, 5970-5975, ISSN: 0897-4756.

Wust, P.; Gneveckow, U.; Johannsen, M.; Bohmer, D.; Henkel, T.; Kahmann, F.; Sehouli, J.; Felix, R.; Ricke, J. \& Jordan, A. (2006). Magnetic nanoparticles for interstitial thermotherapy - feasibility, tolerance and achieved temperatures. Int. J. Hyperthermia, Vol. 22, No 8, 673-685, ISSN: 0265-6736.

Xue, B. \& Sun, Y. (2001). Protein adsorption equilibria and kinetics to a poly(vinyl alcohol)based magnetic affinity support. J. Chromatogr. A, Vol. 921, No 2, 109-119, ISSN: 0021-9673.

Yan, X. D.; Scherphof, G. L. \& Kamps, J. A. A. M. (2005). Liposome opsonization. J. Liposome Res., Vol. 15, No 1-2, 109-139, ISSN: 0898-2104.

Yee, C.; Kataby, G.; Ulman, A.; Prozorov, T.; White, H.; King, A.; Rafailovich, M.; Sokolov, J. \& Gedanken, A. (1999). Self-assembled monolayers of alkanesulfonic and phosphonic acids on amorphous iron oxide nanoparticles. Langmuir, Vol. 15, No 21, 7111-7115, ISSN: 0743-7463.

Yu, H.; Chen, M.; Rice, P. M.; Wang, S. X.; White, R. L. \& Sun, S. H. (2005). Dumbbell-like bifunctional $\mathrm{Au}-\mathrm{Fe}_{3} \mathrm{O}_{4}$ nanoparticles. Nano Lett., Vol. 5, No 2, 379-382, ISSN: 15306984.

Zhang, Y.; Kohler, N. \& Zhang, M. Q. (2002). Surface modification of superparamagnetic magnetite nanoparticles and their intracellular uptake. Biomaterials, Vol. 23, No 7, 1553-1561, ISSN: 0142-9612. 


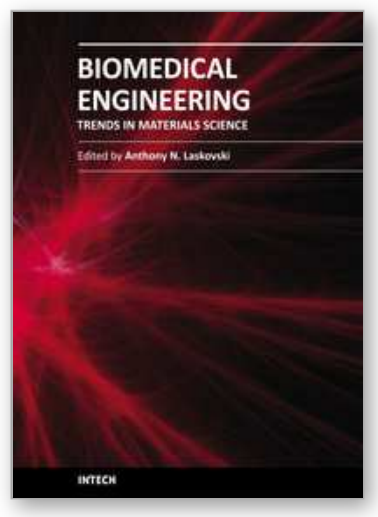

\author{
Biomedical Engineering, Trends in Materials Science \\ Edited by Mr Anthony Laskovski
}

ISBN 978-953-307-513-6

Hard cover, 564 pages

Publisher InTech

Published online 08, January, 2011

Published in print edition January, 2011

Rapid technological developments in the last century have brought the field of biomedical engineering into a totally new realm. Breakthroughs in materials science, imaging, electronics and, more recently, the information age have improved our understanding of the human body. As a result, the field of biomedical engineering is thriving, with innovations that aim to improve the quality and reduce the cost of medical care. This book is the second in a series of three that will present recent trends in biomedical engineering, with a particular focus on materials science in biomedical engineering, including developments in alloys, nanomaterials and polymer technologies.

\title{
How to reference
}

In order to correctly reference this scholarly work, feel free to copy and paste the following:

Laudemir Carlos Varanda, Miguel Jafelicci Júnior and Watson Beck Júnior (2011). Magnetic and Multifunctional Magnetic Nanoparticles in Nanomedicine: Challenges and Trends in Synthesis and Surface Engineering for Diagnostic and Therapy Applications, Biomedical Engineering, Trends in Materials Science, Mr Anthony Laskovski (Ed.), ISBN: 978-953-307-513-6, InTech, Available from:

http://www.intechopen.com/books/biomedical-engineering-trends-in-materials-science/magnetic-andmultifunctional-magnetic-nanoparticles-in-nanomedicine-challenges-and-trends-in-synthes

\section{INTECH}

open science | open minds

\author{
InTech Europe \\ University Campus STeP Ri \\ Slavka Krautzeka 83/A \\ 51000 Rijeka, Croatia \\ Phone: +385 (51) 770447 \\ Fax: +385 (51) 686166 \\ www.intechopen.com
}

\author{
InTech China \\ Unit 405, Office Block, Hotel Equatorial Shanghai \\ No.65, Yan An Road (West), Shanghai, 200040, China \\ 中国上海市延安西路65号上海国际贵都大饭店办公楼405单元 \\ Phone: +86-21-62489820 \\ Fax: +86-21-62489821
}


(C) 2011 The Author(s). Licensee IntechOpen. This chapter is distributed under the terms of the Creative Commons Attribution-NonCommercialShareAlike-3.0 License, which permits use, distribution and reproduction for non-commercial purposes, provided the original is properly cited and derivative works building on this content are distributed under the same license. 